\title{
LIMA (v1.0): A quasi two-moment microphysical scheme driven by a multimodal population of cloud condensation and ice freezing nuclei
}

\author{
B. Vié ${ }^{1}$, J.-P. Pinty ${ }^{2}$, S. Berthet ${ }^{3}$, and M. Leriche ${ }^{2}$ \\ ${ }^{1}$ CNRM-GAME, Météo-France \& CNRS, 42 avenue Gaspard Coriolis, 31057 Toulouse, France \\ ${ }^{2}$ Laboratoire d'Aérologie, University of Toulouse/CNRS, 14 avenue Edouard Belin, 31400 Toulouse, France \\ ${ }^{3}$ Laboratoire d'Etudes en Géophysique et Océanographie Spatiales, CNRS/IRD/University of Toulouse/CNES, \\ 14 avenue Edouard Belin, 31400 Toulouse, France
}

Correspondence to: B. Vié (benoit.vie@meteo.fr)

Received: 15 July 2015 - Published in Geosci. Model Dev. Discuss.: 10 September 2015

Revised: 10 December 2015 - Accepted: 17 December 2015 - Published: 10 February 2016

\begin{abstract}
The paper describes the LIMA (Liquid Ice Multiple Aerosols) quasi two-moment microphysical scheme, which relies on the prognostic evolution of an aerosol population, and the careful description of the nucleating properties that enable cloud droplets and pristine ice crystals to form from aerosols. Several modes of cloud condensation nuclei $(\mathrm{CCN})$ and ice freezing nuclei (IFN) are considered individually. A special class of partially soluble IFN is also introduced. These "aged" IFN act first as CCN and then as IFN by immersion nucleation at low temperatures.
\end{abstract}

All the CCN modes are in competition with each other, as expressed by the single equation of maximum supersaturation. The IFN are insoluble aerosols that nucleate ice in several ways (condensation, deposition and immersion freezing) assuming the singular hypothesis. The scheme also includes the homogeneous freezing of cloud droplets, the HallettMossop ice multiplication process and the freezing of haze at very low temperatures.

LIMA assumes that water vapour is in thermodynamic equilibrium with the population of cloud droplets (adjustment to saturation in warm clouds). In ice clouds, the prediction of the number concentration of the pristine ice crystals is used to compute explicit deposition and sublimation rates (leading to free under/supersaturation over ice). The autoconversion, accretion and self-collection processes shape the raindrop spectra. The initiation of the large crystals and aggregates category is the result of the depositional growth of large crystals beyond a critical size. Aggregation and riming are computed explicitly. Heavily rimed crystals (graupel) can experience a dry or wet growth mode. An advanced version of the scheme includes a separate hail category of particles forming and growing exclusively in the wet growth mode. The sedimentation of all particle types is included.

The LIMA scheme is inserted into the Meso-NH cloudresolving mesoscale model. The flexibility of LIMA is illustrated by two 2-D experiments. The first one highlights the sensitivity of orographic ice clouds to IFN types and IFN concentrations. Then a squall line case discusses the microstructure of a mixed-phase cloud and the impacts of pure $\mathrm{CCN}$ and IFN polluting plumes. The experiments show that LIMA responds well to the complex nature of aerosol-cloud interactions, leading to different pathways for cloud and precipitation formation.

\section{Introduction}

As stressed by the Aerosols, Clouds, Precipitation and Climate (ACPC) Steering Committee (see ACPC, 2009), "the aerosol, clouds and precipitation are a strongly coupled system, but the nature of this coupling and its sensitivity to perturbations in one of the elements is poorly understood". Therefore a central question addressed by the ACPC initiative, and a difficult challenge for cloud modelling, is "How do the amount and properties of the atmospheric aerosol 
affect cloud microstructure and precipitation-forming processes?"

The complex interactions between aerosol particles, clouds and precipitation strongly affect the evolution of the atmosphere and its dynamics at all temporal and spatial scales. Accounting for this interplay is important for high-resolution cloud modelling (aerosols influence the precipitation-forming processes in clouds) and for climate forcing (aerosols influence the radiative-convective equilibrium in many ways), as analysed by Rosenfeld et al. (2008). Observation-based studies have shown the impact of aerosols on clouds and precipitation. Storer et al. (2014) performed a statistical study of tropical deep convective clouds in the eastern Atlantic, based on 4-year Cloudsat observations and aerosol data from the GEMS project. They found a significant convective invigoration for cases with high dust loads. Other observational evidence of the aerosol impacts on clouds includes ship tracks (Ferek et al., 2000) or smoke from forest fires (Andreae et al., 2004). In contrast, Wall et al. (2014) concluded that the signal of the aerosol indirect effect is so small that it is difficult to verify with satellite observations, and natural environmental differences must also be considered when aerosol plumes are released in an air mass.

Several mechanisms have been proposed to depict the dual impact of aerosols, linked to their radiative properties, their ability to diffuse and to absorb solar radiation, or to their microphysical composition and ability to act as cloud condensation nuclei (CCN) and/or ice freezing nuclei (IFN) (see for example the review by Tao et al., 2012). The nucleating efficiency directly impacts the number and size distribution of cloud particles (Twomey, 1977), which affects other cloud processes, such as the formation of precipitating hydrometeors (Albrecht, 1989) and cloud dynamics. It is then imperative to take these effects into account in order to limit the physical uncertainties in cloud simulations, as concluded by Muhlbauer et al. (2013) from the 2012 International Cloud Modelling Workshop (funded by the WMO) on the state of the art in cloud modelling. There is a clear trend towards representing the aerosol processing in clouds (e.g. Saleeby and van den Heever, 2013; Lebo and Morrison, 2013; Thompson and Eidhammer, 2014), but large uncertainties remain, especially in ice initiation, and results are crucially dependent on the approach used for aerosol processing.

Two methods are currently available in cloud microphysics modelling. Bin models explicitly predict the number of particles for several size categories, but for a computational cost that makes them inappropriate for 3-D simulations with large domains, or for operational and regional climate applications. Bulk microphysical schemes, on the other hand, usually predict one (then called one-moment schemes) or more moments of the particle size distribution for a limited number of liquid and solid water species. One-moment schemes only predict the mass mixing ratio of some water species, and are therefore insensitive to the impact of aerosols on clouds. Two-moment schemes are now widely used. They predict both the mass mixing ratio and the number concentration for some species, and have proved more powerful than one-moment schemes (Meyers et al., 1997; Cohard and Pinty, 2000b; Seifert and Beheng, 2006; Milbrandt and Yau, 2005a; Morrison et al., 2009, among others).

The prediction of the cloud droplet number concentration in two-moment schemes relies on the activation of the $\mathrm{CCN}$ following classical Köhler theory. Therefore, the CCN concentrations (or supersaturation spectra) are needed. However, most of the current two-moment schemes (e.g. Milbrandt and Yau, 2005b; Morrison et al., 2005; Morrison and Grabowski, 2007; Seifert and Beheng, 2006) assume a constant, spatially homogeneous, single-mode CCN population. They are thus unable to represent multimodal aerosol populations which classically have three size modes (Aitken, accumulation and coarse modes). They also neglect important effects such as aerosol depletion by activation and below-cloud scavenging, or externally mixed aerosol populations across the simulation domain. Some recent schemes improve matters by representing a prognostic $\mathrm{CCN}$ population. They account for aerosol depletion (e.g. Lim and Hong, 2010; Kogan, 2013; Lebo and Morrison, 2013), but are limited to a single CCN type and size distribution.

The question of ice nucleation from IFN remains even more open in cloud microphysics. The different mechanisms for heterogeneous ice nucleation are not clearly established, but suggest a strong dependence on IFN composition. Although their formulations differ, all recent parameterizations (e.g. Diehl and Wurzler, 2004; Khvorostyanov and Curry, 2004; Phillips et al., 2008; Barahona and Nenes, 2009) describing heterogeneous ice formation consider the IFN chemistry, surface properties and amounts. However, most of the two-moment microphysical schemes cited above and including ice nucleation rely on the classic formulation by Meyers et al. (1992) and therefore do not represent the link between the aerosol population and heterogeneous ice formation.

The two-moment, mixed-phase scheme proposed by Saleeby and van den Heever (2013) stands out from the others and provides a much better representation of aerosol and cloud interactions. It features a prognostic evolution of nine aerosol species, including surface production of dust and sea salt, aerosol processing in cloud and rainfall scavenging, and the aerosol radiative effect. The cloud droplet nucleation is based on look-up tables built from bin model runs, with a different solubility for each aerosol species. Ice nucleation follows the empirical parameterization by DeMott et al. (2010), based on the number of non-sea-salt aerosols larger than $0.5 \mu \mathrm{m}$. However, this parameterization does not differentiate between aerosol species.

Similarly, Thompson and Eidhammer (2014) added an aerosol scheme to the original cloud microphysical scheme of Thompson et al. (2008). Two prognostic variables are then used to predict the number concentration of hydrophilic and hydrophobic aerosols. The aerosol surface emissions differ from Saleeby and van den Heever (2013). The production of 
aerosols is based on the initial aerosol concentration and depends on the mean surface wind. Thompson and Eidhammer (2014) concluded that their method produced better results than holding initial aerosol concentrations constant.

Meso-NH (Lafore et al., 1998) is a 3-D non-hydrostatic core model specifically dedicated to the study of resolved clouds. The nucleation of aerosol particles is dependent on water vapour amounts brought by vertical updrafts. The resolution of the vertical motion is therefore an essential point in the computation of nucleation processes (Morrison and Grabowski, 2008). Meso-NH includes different cloud parameterizations, such as the ICE3 one-moment scheme (Pinty and Jabouille, 1998) used in the AROME French mesoscale operational model (Seity et al., 2011), and twomoment schemes for warm clouds following Cohard and Pinty (2000a) and for marine stratocumulus (Khairoutdinov and Kogan, 2000; Geoffroy et al., 2008).

This work presents the elaboration of a new mixed-phase quasi two-moment scheme in Meso-NH, called LIMA (Liquid, Ice, Multiple Aerosols), which includes a detailed representation of aerosol-cloud interactions. This scheme integrates a prognostic representation of the polydisperse, heterogeneously distributed aerosol population (AP), and accounts for the distinct nucleabilities of the different aerosol species, both for cloud droplets and ice crystals. The nucleation scheme developed for warm, and then cold, microphysics is presented in Sect. 2. Section 3 shows the performance of LIMA for 2-D, idealized simulations of cold and mixed-phase clouds with different background APs. Finally, the important features of the scheme and the perspectives for extending its applicability are discussed in Sect. 4.

\section{Description of the quasi two-moment microphysical scheme}

As in the majority of bulk schemes, LIMA describes the transfers of condensate between the water categories: vapour, liquid and ice. LIMA inherits the five water species of the ICE3 scheme (Pinty and Jabouille, 1998; Caniaux et al., 1994) (cloud droplets, raindrops, pristine ice crystals, snow/aggregates and graupel). Hail is considered either as a full sixth category or combined with graupel to form an extended class of heavily rimed ice particles. In addition to the mass mixing ratios, the scheme predicts the number concentration of the cloud droplets, the raindrops and the pristine ice crystals. The particle sizes for each category follow a generalized gamma distribution.

Since LIMA focuses explicitly on aerosol-cloud interactions, in the current implementation, the two-moment approach is obvious for the liquid species and the pristine ice only. In contrast, given the wide range of shapes, sizes, particle densities and other characteristics of precipitating ice hydrometeors (snow, graupel and hail) subject to riming, it is unclear whether a double-moment description of these
Table 1. Example aerosol size distribution parameters and aerosol type in the LIMA scheme.

\begin{tabular}{llrrl}
\hline $\begin{array}{l}\text { Aerosol } \\
\text { mode }\end{array}$ & $\begin{array}{l}\text { Chemical } \\
\text { type }\end{array}$ & $\begin{array}{r}d_{X} \\
(\mu \mathrm{m})\end{array}$ & $\sigma_{X}$ & $\begin{array}{l}\text { Nucleating } \\
\text { ability }\end{array}$ \\
\hline 1 & Sea salt & 0.8 & 1.9 & CCN \\
2 & Sulfate & 0.5 & 1.6 & CCN \\
3 & Organics & 0.2 & 1.6 & Coated IFN \\
4 & Black carbon & 0.2 & 1.6 & Coated IFN \\
5 & Organics & 0.2 & 1.6 & IFN \\
6 & Black carbon & 0.2 & 1.6 & IFN \\
7 & Dust & 0.8 & 1.9 & IFN \\
8 & Dust & 3 & 1.6 & IFN \\
\hline
\end{tabular}

species allows a better treatment of the physical processes, and so a single-moment approach is chosen.

This part first details the representation of aerosols in LIMA. Then, the CCN activation and warm processes leading to rain formation are presented, and the IFN nucleation and cold and mixed-phase processes are described.

\subsection{A prognostic scheme for a multimodal AP}

\subsubsection{Multiple aerosol modes}

The processes of cloud droplet activation and ice crystal nucleation are based on a prognostic multi-modal, heterogeneous AP. In LIMA, the AP is represented by the superimposition of several aerosol modes. Each mode is defined by its chemical composition (e.g. dust, sea salt) and its ability to act either as CCN, IFN or coated IFN, depending on solubility. The log-normal particle size distribution (PSD) of each mode is characterized by a modal diameter ${ }^{1} d_{X}$ and width $\sigma_{X}$ which do not vary during the simulation, and a total concentration $N_{X}$ :

$n\left(d_{a}\right) \mathrm{d} d_{a}=\frac{N_{X}}{\sqrt{2 \pi} d_{a} \ln \left(\sigma_{X}\right)} e^{-\left(\frac{\ln \left(d_{a} / d_{X}\right)}{\sqrt{2} \ln \left(\sigma_{X}\right)}\right)^{2}} \mathrm{~d} d_{a}$.

The scheme allows the superimposition of an unlimited number of aerosol modes, enabling a realistic representation of any AP. Table 1 gives the default configuration of LIMA. The supersaturation spectra of each CCN mode must be available to compute their activation properties. The IFN and coated IFN are limited to the organics, black carbon and dust, to fit with the IFN heterogeneous nucleation parameterization of Phillips et al. (2008), which is presented below. The IFN modes can be either pure species or internally mixed with fixed fractions of several species.

\footnotetext{
${ }^{1}$ Lower-case $d$ are used for aerosols, upper-case $D$ for hydrometeors.
} 


\subsubsection{Prognostic evolution of the AP}

In LIMA, two prognostic variables are associated with each aerosol mode acting as CCN or IFN. LIMA predicts $N^{\text {free }}$, the number concentration of free aerosols, attached to each $\mathrm{CCN}$ and IFN type, and $N^{\text {acti }}$, the number of activated aerosols in cloud droplets when considering $\mathrm{CCN}$, or $N^{\text {nucl }}$, the number of nucleated aerosols in ice crystals for the IFN. The coated IFN in LIMA represent aged, partially soluble IFN. They possess the dual property of serving first as CCN to form cloud droplets, and later of freezing these droplets by immersion nucleation. Therefore, for each coated IFN mode, three prognostic variables are needed: $N^{\text {free }}, N^{\text {acti }}$ and $N^{\text {nucl }}$.

The aerosol population is transported by the resolved and subgrid scale (turbulence, convection) flow. The aerosols are depleted (transferred from the $N^{\text {free }}$ reservoir to $N^{\text {acti }}$ or $N^{\text {nucl }}$ ) by activation of cloud droplets or nucleation of ice crystals as detailed hereafter. They are also regenerated (reinjected into $N^{\text {free }}$ from the $N^{\text {acti }}$ or $N^{\text {nucl }}$ reservoirs) in the case of cloud droplet evaporation or pristine ice crystal sublimation. All these processes are conservative regarding the total number of aerosols in each mode (e.g. $N^{\text {free }}+N^{\text {acti }}$ for a $\mathrm{CCN}$ mode) before the formation of the first precipitating particles.

In the current implementation of LIMA, there are no aerosol sources at the surface. The fields of aerosol are initialized, and enter the domain of simulation in case of lateral inflow conditions. Aerosol dry deposition and ageing processes are not considered either. Since this scheme was designed for short-term, high-resolution cloud simulations, these approximations were deemed acceptable. The Meso$\mathrm{NH}$ model includes optional modules for dust and sea salt emissions, and a more complex aerosol scheme ORILAM (Tulet et al., 2005). The interfacing of LIMA with these modules is under examination.

\subsubsection{Below-cloud washing out of aerosols}

The below-cloud scavenging of aerosols by rain in LIMA follows Berthet et al. (2010). Instead of assuming a representative diameter for all raindrops, their parameterization takes the size distributions of both raindrops and aerosol particles into account. The collection efficiency of an aerosol by a raindrop is parameterized after Slinn (1983), and represents the three best understood collection processes: Brownian diffusion, interception, and inertial impaction, ordered by increasing aerosol size.

The Gauss-Laguerre quadrature (Press et al., 1992) is used to integrate the collection efficiency over the whole spectrum of raindrop sizes, yielding the scavenging coefficient for given aerosol particle sizes. Then, a Gauss-Hermite algorithm integrates over the aerosol size distribution to compute the total rate of below-cloud scavenging.

Since the scavenging efficiency depends on the aerosol particle size, the aerosol modes are affected differently. The washing out process should modify the particle size distribution of the individual modes of the AP as well. However, and because the mass mixing ratio of the aerosols is not predicted in LIMA, the PSD parameters of each mode are held fixed, and only the aerosol concentrations are modified, i.e. depleted in this case. Figure 1 in Berthet et al. (2010) shows the scavenging coefficient as a function of the aerosol particle diameter, for different rain intensities. A minimum is reached for $0.1 \mu \mathrm{m}<d_{a}<1 \mu \mathrm{m}$, with limited variations in this range. Therefore, the approximation in LIMA is reasonable for most of the aerosol $d_{X}$ modes between 0.1 and $1 \mu \mathrm{m}$, considering that $\sigma_{X}$ values around 2 produce sharp enough PSDs for these $d_{X}$ values. The error induced by this approximation may be more serious for larger size modes, such as mode 8 in Table $1\left(d_{X}=3 \mu \mathrm{m}\right)$, but since the number of particles in large modes is generally limited, and easily activated, the resulting error on cloud properties should remain acceptable.

\subsubsection{Radiative impact of aerosols}

Meso-NH includes a detailed radiative transfer scheme (Fouquart and Bonnel, 1980; Mlawer et al., 1997) for the aerosols. Following Aouizerats et al. (2010), optical parameters (extinction coefficient, single scattering albedo and asymmetry factor) are computed for a large variety of aerosol types based on the size distribution and aerosol mass mixing ratio. Furthermore, the fraction of cloud droplets formed on coated IFN is tagged (see next section), so appropriate optical properties can be introduced to simulate the semi-indirect aerosol effect (Johnson et al., 2004). Since LIMA and the radiative transfer scheme share the same aerosol loading, the Meso-NH model is suitable to study many radiative impacts of aerosols on clouds and precipitation.

\subsection{CCN activation parameterization}

The parameterization of $\mathrm{CCN}$ activation described below is based on Cohard et al. (1998), extended to a multimodal population of $\mathrm{CCN}$.

\subsubsection{CCN activation spectrum}

In Köhler theory, an aerosol particle is activated and becomes a cloud droplet whenever the ambient supersaturation $S$ exceeds the particle's critical supersaturation $S_{\text {crit }}$, which depends on aerosol size and composition (surfactant, dissolved salt, insoluble fraction). Therefore, for a given AP and ambient supersaturation $S$, all aerosol particles verifying $S_{\text {crit }}<S$, and these only, are activated.

Cohard and Pinty (2000a) stressed the difficulty of explicitly predicting peak values of $S$ for CCN activation because this quantity is highly non-homogeneous in both space and time at micrometre scale. Furthermore, the equilibrium between $\mathrm{CCN}$ activation and water vapour condensation is hardly resolved until short timescales are considered. Instead, the parameterization of Cohard et al. (1998) is based 
on an approximation of the maximum supersaturation $S_{\max }$ and on an extension of Twomey's " $C S^{k}$ " law:

$N_{\mathrm{CCN}}=C S_{\max }^{k} F\left(\mu, \frac{k}{2}, \frac{k}{2}+1,-\beta S_{\max }^{2}\right)$,

where $C, k, \mu$ and $\beta$ depend on the aerosol chemical composition, and $F$ is the hypergeometric function as proposed by Cohard et al. (1998). The total concentration $N_{X}$ (Eq. 1) is related to the activation spectrum parameters (Cohard et al., 2000) by

$N_{X}=\frac{C}{\beta^{k / 2}} \frac{\Gamma(k / 2+1) \Gamma(\mu-k / 2)}{\Gamma(\mu)}$,

where $\Gamma()$ is the Gamma function.

This formulation of the activation spectrum copes better with high supersaturations, for which the number of activable $\mathrm{CCN}$ is limited by the number of available $\mathrm{CCN}$, and therefore allows the competition between several $\mathrm{CCN}$ modes to be treated.

\subsubsection{Diagnostic $S_{\max }$ computation}

The evolution of $S$ is described by Eq. (4), in which three terms account for the effects of a convective ascent (1) with $\omega$ a vertical velocity, the growth of droplets by vapour condensation (2) and a cooling rate (3), e.g. pure radiative cooling as in the case of fog:

$$
\frac{\mathrm{d} S}{\mathrm{~d} t}=\underbrace{\psi_{1} \omega}_{(1)}-\underbrace{\psi_{2} \frac{\mathrm{d} q_{\mathrm{c}}}{\mathrm{d} t}}_{(2)}+\underbrace{\psi_{3} \frac{\mathrm{d} T}{\mathrm{~d} t}}_{(3)},
$$

where $\psi_{1}, \psi_{2}$ and $\psi_{3}$ are thermodynamic functions depending on the temperature and pressure.

Following Pruppacher and Klett (1997), the rate of change of cloud water content can be approximated by

$$
\frac{\mathrm{d} q_{\mathrm{c}}}{\mathrm{d} t} \simeq 2 \pi \frac{\rho_{w}}{\rho_{a}}(2 G)^{3 / 2} S \int_{0}^{S} n\left(S^{\prime}\right)\left[\int_{\tau\left(S^{\prime}\right)}^{t} S\left(t^{\prime}\right) \mathrm{d} t^{\prime}\right]^{1 / 2} \mathrm{~d} S^{\prime},
$$

where $G\left(D_{\mathrm{c}}, T, P\right)$ represents the growth of droplets of diameter $D_{\mathrm{c}} . n(S) \mathrm{d} S$ is the number of CCN having a critical saturation between $S$ and $S+\mathrm{d} S$.

For a single CCN mode, such as in Cohard et al. (2000), a lower bound approximation is introduced by Twomey (1959) to evaluate the integral of supersaturation in Eq. (5). So, assuming

$n(S)=k C S^{k-1}\left(1+\beta S^{2}\right)^{-\mu}$

to recover Eq. (2) when integrating over the supersaturation $S$, the CCN activation spectrum of a multimodal AP can be modelled as

$$
n(S)=\sum_{m \text { modes }} k_{m} C_{m} S^{k_{m}-1}\left(1+\beta_{m} S^{2}\right)^{-\mu_{m}} .
$$

Then, following Twomey (1959), an upper bound for the rate of change of cloud water content is estimated as

$$
\begin{aligned}
& \frac{\mathrm{d} q_{\mathrm{c}}}{\mathrm{d} t}> \\
& \sum_{m \text { modes }} 2 \pi \frac{\rho_{w}}{\rho_{a}} \frac{G^{3 / 2}}{\left(\psi_{1} \omega+\psi_{3} \frac{\mathrm{d} T}{\mathrm{~d} t}\right)^{1 / 2}} k_{m} C_{m} S^{k_{m}+2} B_{m} F_{m, S},
\end{aligned}
$$

where, for clarity, we noted $F_{m, S}=F\left(\mu_{m}, \frac{k_{m}}{2}, \frac{k_{m}}{2}+\right.$ $\left.\frac{3}{2},-\beta_{m} S^{2}\right)$, and $B_{m}=B\left(\frac{k_{m}}{2}, \frac{3}{2}\right)$ with $B$ the Beta function. The derivation of Eq. (8) includes the cooling rate term of Eq. (4) which is often neglected in previous works.

The maximum of supersaturation verifies $\frac{\mathrm{d} S}{\mathrm{~d} t}=0$; so, combining Eqs. (4) and (8), we obtain

$\sum_{m \text { modes }} k_{m} C_{m} S_{\max }^{k_{m}+2} B_{m} \mathrm{~F}_{m, S_{\max }}<\frac{\rho_{a}\left(\psi_{1} \omega+\psi_{3} \frac{\mathrm{d} T}{\mathrm{~d} t}\right)^{\frac{3}{2}}}{\rho_{w} 2 \pi G^{\frac{3}{2}} \psi_{2}}$,

from which $S_{\max }$ is computed using the Ridder algorithm (Press et al., 1992). $S_{\max }$ depends on both the atmospheric conditions and the aerosol modes (number concentrations, size distributions and activating abilities), and therefore accounts for the competition between several aerosol modes.

\subsubsection{CCN activation}

The value of $S_{\max }$ is common to all CCN modes. The total number concentration $N^{\text {free }}+N^{\text {acti }}$ per mode is the sum of the available and activated aerosols, which is equal to $N_{X}$ (see Eqs. 1 and 3). Thus by definition, the number of activable aerosols of a given mode at the current time $t$ is $N_{\mathrm{CCN}}\left(S_{\mathrm{max}}\right)$. For each given mode, it is compared to $N^{\text {acti }}$, the number of aerosols that were already activated at the previous time step $t-\Delta t$. If $N_{\mathrm{CCN}}\left(S_{\max }\right)<N^{\text {acti }}$, all the aerosols with a diameter larger than $d_{\text {crit }}\left(S_{\max }\right)$ are already activated, and no further activation is possible. If $N_{\mathrm{CCN}}\left(S_{\max }\right)>N^{\text {acti }}$, additional aerosols, $N_{\mathrm{CCN}}\left(S_{\max }\right)-N^{\text {acti }}$, are activated. Therefore, at each time step, the numbers of free and activated aerosols are updated according to

$$
\begin{aligned}
& \Delta N_{\mathrm{CCN}}=\operatorname{Max}\left(0, N_{\mathrm{CCN}}\left(S_{\max }\right)-N^{\text {acti }}(t-\Delta t)\right), \\
& N^{\text {free }}(t)=N^{\text {free }}(t-\Delta t)-\Delta N_{\mathrm{CCN}}, \\
& N^{\text {acti }}(t)=N^{\text {acti }}(t-\Delta t)+\Delta N_{\mathrm{CCN}} .
\end{aligned}
$$

\subsection{Collision and coalescence processes}

\subsubsection{Autoconversion}

The autoconversion of cloud droplets into raindrops is parameterized after Berry and Reinhardt (1974) and Cohard and Pinty (2000a) (see also Gilmore and Straka, 2008). Berry and Reinhardt (1974) simulated the evolution by collection of a unimodal population of cloud droplets into a bimodal distribution of cloud droplets and raindrops. They repeated 
this study for different initial distribution spreads and mean radii and proposed simple expressions to compute the rain formation rate. Using their notations, a raindrop mixing ratio $L_{2}^{\prime}$ develops in a time $T_{2}$ (note that there is a mistake in their Eq. (16) for $T_{2}$, which is correctly expressed in their Fig. 8). By converting their expressions into LIMA units, the autoconversion rate is obtained as $L / \tau$, where $L\left(\mathrm{~kg} \mathrm{~m}^{-3}\right)$ and $\tau$ (s) depend on the mean-volume droplet diameter $D_{\mathrm{c}}(\mathrm{m})$, the corresponding standard deviation $\sigma_{\mathrm{c}}(\mathrm{m})$, and the cloud droplet mixing ratio $r_{\mathrm{c}}\left(\mathrm{kg} \mathrm{kg}^{-1}\right)$. The $10^{20}$ and $10^{6}$ factors, and the presence of $\rho_{a}$, account for unit conversion. The 1/16 and 0.5 factors account for the change between particle radius in Berry and Reinhardt (1974) and diameter in LIMA.

$$
\begin{aligned}
L & =2.710^{-2}\left(\frac{1}{16} 10^{20} \sigma_{\mathrm{c}}^{3} D_{\mathrm{c}}-0.4\right) \rho_{a} r_{\mathrm{c}} \\
\tau & =3.7\left(0.5 \times 10^{6} \sigma_{\mathrm{c}}-7.5\right)^{-1} \frac{1}{\rho_{a} r_{\mathrm{c}}}
\end{aligned}
$$

As explained in Cohard and Pinty (2000a), the raindrop number concentration production rate proposed by Berry and Reinhardt (1974) is kept only for the initial formation of small raindrops. In LIMA, when the raindrop mean-volume radius exceeds the hump radius defined by Berry and Reinhardt (1974), it is assumed that the autoconversion does not modify the mean-volume diameter, and therefore the raindrop number concentration production rate $\left(\mathrm{kg}^{-1} \mathrm{~s}^{-1}\right)$ is reduced to $N_{\mathrm{r}} / r_{\mathrm{r}} \times L / \tau$.

\subsubsection{Accretion, self-collection and raindrop break-up}

Berry and Reinhardt (1974) made the distinction between the time $T_{2}$ needed for a characteristic radius of the rain spectrum to reach the value of $50 \mu \mathrm{m}$, and the time $T_{H} 1.2 \times T_{2}$ at which a hump shows up on the rain spectrum (with their notations). During the $T_{2}-T_{H}$ transition, their autoconversion rate is supposed to include cloud droplet accretion and raindrop self-collection. Therefore, accretion and raindrop selfcollection are activated in LIMA once the raindrop mixing ratio $r_{\mathrm{r}}$ reaches $1.2 \times L$.

The approximate collection kernels of Long (1974) are used to compute numerical solutions of the collection equation for both accretion and self-collections:

$$
K\left(D_{1}, D_{2}\right)= \begin{cases}K_{2}\left(D_{1}^{6}+D_{2}^{6}\right) & \text { if } D_{1} \leq 100 \mu \mathrm{m} \\ K_{1}\left(D_{1}^{3}+D_{2}^{3}\right) & \text { if } D_{1} \geq 100 \mu \mathrm{m}\end{cases}
$$

with $K_{2}=2.59 \times 10^{15} \mathrm{~m}^{-3} \mathrm{~s}^{-1}$ and $K_{1}=3.03 \times 10^{3} \mathrm{~s}^{-1}$. The derived expressions for accretion and self-collection rates can be found in Cohard and Pinty (2000a).

Collisional raindrop break-up is included as a selfcollection efficiency, through a multiplying factor that slows the self-collection process for raindrops larger than $600 \mu \mathrm{m}$ in diameter, and disables it over $2000 \mu \mathrm{m}$.

\subsection{IFN heterogeneous freezing}

The heterogeneous ice nucleation process is still an open question and the subject of a long-standing debate. So far, no satisfactory theoretical framework, equivalent to the Köhler CCN activation theory, has been firmly established to describe the different pathways of ice nucleation on IFN substrates.

The nature of heterogeneous ice nucleation itself is not yet clearly understood. It is sometimes described using the stochastic hypothesis (the probability of ice nucleation depends on the duration of exposure to negative temperatures) or using the singular hypothesis (each IFN has a unique critical temperature below which freezing occurs instantly). While both hypotheses seem justified, the singular hypothesis seems more appropriate (Niedermeier et al., 2011) when considering IFN with heterogeneous surface properties.

\subsubsection{Phillips et al. (2008) parameterization}

These considerations are the basis of the empirical parameterization of heterogeneous ice nucleation proposed by Phillips et al. (2008) with revision in Phillips et al. (2013), which has been implemented in LIMA. The parameterization does not distinguish between the different nucleation processes, but instead treats them as a whole, and therefore represents nucleation by condensation, immersion freezing and deposition equally.

A fundamental assumption of the scheme is that ice nucleation occurs at preferred active sites on the surface of aerosol particles, and that the number of sites is proportional to the total surface area of the aerosols. The surface density of these sites depends on the chemical composition, and therefore the scheme distinguishes three aerosol species, namely dust and metallic particles (DM), inorganic black carbon (BC) and insoluble organics $(\mathrm{O})$. The nucleating properties are constrained by simultaneous observations of insoluble aerosols in the troposphere, and by ice nucleation rate measurements in a continuous flow diffusion chamber (CFDC) under controlled conditions of temperature and supersaturation.

From a large observational data set, Phillips et al. (2008) derived the fractional contribution $\alpha_{X}$ of each IFN species ( $X=\mathrm{DM}, \mathrm{BC}, \mathrm{O})$ to the ice concentration in the CFDC, and a reference activity spectrum $N_{\mathrm{i}, \text { ref }}\left(T, S_{\mathrm{i}}\right)$, which gives the average number of ice crystals formed at a given temperature and supersaturation over ice $\left(S_{\mathrm{i}}\right)$. On the other hand, insoluble aerosol observations were used to compute the aerosol

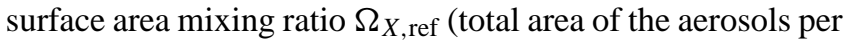
kilogram of dry air, $\mathrm{m}^{2} \mathrm{~kg}^{-1}$ ) for each IFN type.

The number concentration of active IFN of type $X$ is then computed by the integration over the particle size $d_{a}$, and considering that particles with a diameter less than $0.1 \mu \mathrm{m}$ 
cannot serve as nuclei:

$$
N_{\mathrm{i}, X}^{*}=\int_{0.1 \mu \mathrm{m}}^{\infty}\left\{1-\exp \left[-\mu_{X}\left(d_{a}, S_{\mathrm{i}}, T\right)\right]\right\} \frac{\mathrm{d} N_{X}}{\mathrm{~d} d_{a}} \mathrm{~d} d_{a},
$$

where $N_{X}$ is the number concentration, and

$\mu_{X}=H_{X}\left(S_{\mathrm{i}}, T\right) \xi(T)\left[\frac{\alpha_{X} N_{\mathrm{i}, \text { ref }}}{\Omega_{X, \text { ref }}}\right] \frac{\mathrm{d} \Omega_{X}}{\mathrm{~d} N_{X}}$.

In Eq. (17), $H_{X}\left(S_{\mathrm{i}}, T\right)$ represents the scarcity of occurrence of ice nucleation for low $S_{\mathrm{i}}$ conditions $\left(H_{X}=1\right.$ for saturated conditions with respect to liquid water), $\xi(T)$ accounts for the progressive reduction of nucleation efficiency for temperatures between -5 and $-2{ }^{\circ} \mathrm{C}$. It is interesting to note that $\mu_{X}$ depends on both the aerosol type (through the

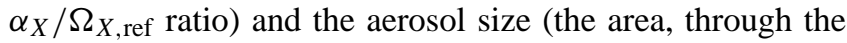
$\mathrm{d} \Omega_{X} / \mathrm{d} N_{X}$ ratio). Furthermore, for warm subzero temperatures, the frozen fraction is small, so $\mu_{X} \ll 1$ and Eq. (16) simplifies into

$N_{\mathrm{i}, X}^{*} \approx H_{X}\left(S_{\mathrm{i}}, T\right) \xi(T)\left[\frac{\alpha_{X} N_{\mathrm{i}, \mathrm{ref}}}{\Omega_{X, \mathrm{ref}}}\right] \Omega_{X}$

to express the proportionality between the number of nucleated IFN and their area.

\subsubsection{Implementation in LIMA}

Under the singular hypothesis, IFN heterogeneous nucleation, like CCN activation, does not depend on time. If an air parcel is exposed to constant $T$ and $S_{\mathrm{i}}$ conditions $^{2}$, there should be no more nucleation beyond the first time step. Thus, IFN nucleation is treated in the same manner as CCN activation. The integration of Eq. (16) is performed at each time step $t$ (see Appendix A for technical details), and therefore returns the number concentration of nucleable particles $N_{\mathrm{i}, X}^{*}(t)$ of the aerosol species ( $\left.X=\mathrm{DM} 1, \mathrm{DM} 2, \mathrm{BC}, \mathrm{O}\right)$. Then the number of aerosols to nucleate at time $t$ is computed as the positive difference between the number of nucleable IFN and the number of IFN previously nucleated:

$$
\begin{aligned}
& \Delta N_{\mathrm{IFN}, X}=\operatorname{Max}\left(0, N_{\mathrm{i}, X}^{*}(t)-N_{X}^{\text {nucl }}(t-\Delta t)\right) \\
& N_{X}^{\text {free }}(t)=N_{X}^{\text {free }}(t-\Delta t)-\Delta N_{\mathrm{IFN}, X} \\
& N_{X}^{\text {nucl }}(t)=N_{X}^{\text {nucl }}(t-\Delta t)+\Delta N_{\mathrm{IFN}, X}
\end{aligned}
$$

In LIMA, coated IFN are treated as aerosols acting first as $\mathrm{CCN}$ to produce tagged cloud droplets which are the reservoir for ice nucleation by immersion. Practically, the same parameterization as for insoluble IFN is used, but the integration of Eq. (16) is performed with $N_{\text {acti }}+N_{\text {nucl }}$, the number of coated IFN that were used to form droplets or ice crystals.

\footnotetext{
${ }^{2}$ In contrast to CCN activation where $S_{\max }$ is defined, the IFN nucleation scheme is based on the grid resolved supersaturation over ice $S_{\mathrm{i}}$
}

The $N_{\text {acti }}+N_{\text {nucl }}$ number concentration grows whenever coated IFN are activated as cloud droplets. Moreover, since $\mathrm{CCN}$ activation depletes the biggest aerosols and not a random sample of the $\mathrm{CCN}$ distribution, the size distribution of the $N_{\text {acti }}+N_{\text {nucl }}$ particles is neither equal to the initial coated IFN size distribution, nor constant in time. However, to avoid considerable complexity in integrating Eq. (16), a log-normal size distribution of $N_{\text {acti }}+N_{\text {nucl }}$ is still assumed, but with constant parameters $\left(d_{X}\right.$ and $\left.\sigma_{X}\right)$ that differ from those of the initial coated IFN mode.

\subsection{Mixed-phase cloud processes}

\subsubsection{IFN-free processes for ice crystal formation}

There are two pathways for the formation of pristine ice crystals without the assistance of IFN. One is the homogeneous freezing of cloud droplets described by Pruppacher (1995) with a nucleation rate fitted from Table 1 of his paper. In contrast, the freezing of raindrops is instantaneous at temperatures below $-35^{\circ} \mathrm{C}$, and frozen raindrops are added to the graupel category. At colder temperatures, below $-40^{\circ} \mathrm{C}$, the freezing of deliquescent aerosol particles, assimilated in LIMA to CCN particles, is considered through the parameterization of Kärcher and Lohmann (2002).

The secondary ice production process by the HallettMossop mechanism (Hallett and Mossop, 1974) is computed. At temperatures between -3 and $-8^{\circ} \mathrm{C}$, an ice splinter is produced each time a graupel particle is rimed with 200 droplets having diameters between 12 and $25 \mu \mathrm{m}$ (Beheng, 1987).

\subsubsection{Pristine ice to snow conversion}

Harrington et al. (1995) proposed an explicit formulation of pristine ice to snow conversion by deposition of water vapour in a two-moment framework. This parameterization is adopted in LIMA, in which only the mass mixing ratio of snow is predicted, and a generalized gamma particle size distribution is assumed:

$n(D) \mathrm{d} D=N \frac{\alpha}{\Gamma(\nu)} \lambda^{\alpha \nu} D^{\alpha \nu-1} e^{-(\lambda D)^{\alpha}} \mathrm{d} D$,

where $\alpha$ and $\nu$ are fixed shape parameters, $N$ is the total number concentration and $\lambda$ is the slope parameter related to the mixing ratio.

As in Harrington et al. (1995), the conversion of pristine ice to snow takes place when ice crystals grow by water deposition beyond a critical diameter $D_{\text {lim }}$, fixed at $125 \mu \mathrm{m}$. Therefore, the number concentration of pristine ice crystals converted to the snow/aggregates category is computed as (their Eq. 19) 


$$
\frac{\mathrm{d} N_{i}}{\mathrm{~d} t}=\left.\frac{\mathrm{d} D}{\mathrm{~d} t}\right|_{D_{\lim }} n_{i}\left(D_{\lim }\right)
$$

and the mass mixing ratio as (first term of their Eq. 20)

$$
\frac{\mathrm{d} r_{i}}{\mathrm{~d} t}=\left.\frac{1}{\rho_{a}} m\left(D_{\lim }\right) \frac{\mathrm{d} D}{\mathrm{~d} t}\right|_{D_{\lim }} n_{i}\left(D_{\lim }\right) .
$$

The mass change of a single ice or aggregate particle is expressed as

$$
\frac{\mathrm{d} m}{\mathrm{~d} t}=S_{\mathrm{i}} C f A_{\mathrm{i}}(T, P)
$$

where $C=C_{1} D$ is the crystal capacity and depends on its size and shape, $A_{\mathrm{i}}(T, P)$ is a thermodynamic function available in textbooks, and $f$ is a ventilation factor. Combining that expression with the mass-diameter relationship $m=$ $\alpha D^{\beta}$, we can derive $\mathrm{d} D / \mathrm{d} t, \mathrm{~d} N_{\mathrm{i}} / \mathrm{d} t$ and $\mathrm{d} r_{\mathrm{i}} / \mathrm{d} t$ rates.

\subsubsection{Graupel and hail processes}

Mixed-phase processes related to graupel are extended from the ICE3 one-moment microphysical scheme. They include the light riming of snow with cloud droplets, the wet/dry growth of graupel when collecting other hydrometeors, and the accretion of rain and aggregates. The freezing of raindrops upon contact with an ice crystal leads to the formation of graupel as frozen drops are not a separate ice category.

After preliminary studies (Lascaux et al., 2006), an optional representation of hail was introduced in LIMA. Hail particles are formed when graupel particles grow in the wet regime (collection of liquid water in excess of what can be frozen at the surface of the graupel) and accordingly a fraction of graupel is transferred into the hail category. The following hail particles grow exclusively in the wet growth mode. Other processes also include the reverse conversion of hail to graupel, and the melting of hailstones.

\subsection{Water deposition and evaporation}

Following Pruppacher and Klett (1997), the size evolution of an evaporating raindrop in an under-saturated environment is expressed as a function of the (negative) water vapour supersaturation $S$, a ventilation factor $f$ and a thermodynamic function $A_{w}(T, P)$ (similar to $A_{\mathrm{i}}(T, P)$ for the deposition of vapour on ice crystals):

$$
\frac{\mathrm{d} D}{\mathrm{~d} t}=\frac{S f A_{w}(T, P)}{D}
$$

This expression is used to compute the evaporation rate after integration over the raindrop spectrum. The number concentration of raindrops is not affected by evaporation, unless the mean volume drop diameter becomes smaller than $82 \mu \mathrm{m}$. Then, all the raindrops are converted into cloud droplets.
As stressed earlier, there is no supersaturation over water in LIMA. The fast condensation and evaporation processes affecting the cloud droplets are the result of an implicit adjustment to reach a strict equilibrium at water saturation (or complete evaporation of cloud droplets) at the end of the time step. Consequently the parameterized activation of the CCN is the first step to forming liquid water clouds.

In ice clouds, where only frozen particles are present, LIMA predicts explicit rates of water vapour deposition or ice sublimation, following Tzivion et al. (1989). This is in contrast with the treatment of the warm clouds because pristine ice concentrations are several orders smaller than cloud droplet concentrations, and so the assumption of water vapour equilibrium at saturation is no longer applicable for cold clouds. Therefore, large supersaturations over ice (up to $40-50 \%$ ) can be found in cold cloud ascents simulated by LIMA.

In the case of mixed-phase conditions (where both cloud droplets and ice crystals are present), an implicit adjustment to liquid water saturation is performed first as the air parcel is initially super or undersaturated. Then, the explicit condensation/evaporation and deposition/sublimation rates are determined following the scheme of Reisin et al. (1996, their Appendix B). The CCN and the IFN budgets are updated in case of full droplet evaporation and pristine ice sublimation, respectively.

\section{Performance of the LIMA scheme}

Two 2-D idealized test cases were simulated with MesoNH to demonstrate the capabilities of the LIMA scheme. An example of orographically induced cold clouds illustrates the impact of IFN properties and IFN concentrations in the parameterization of Phillips et al. (2008). Then, an ensemble of squall line simulations was performed to show the behaviour of LIMA in mixed-phase convective clouds and more specifically to highlight the sensitivity of the cloud structure to a multimodal population of aerosols.

\subsection{Impact of IFN properties and concentration on glaciated clouds}

The 2-D simulation of orographic cold clouds was run on a $1 \mathrm{~km}$ resolution domain of 900 points $(900 \mathrm{~km})$, with 90 uneven vertical levels. The simulation was initialized with the temperature and humidity profiles shown in Fig. 1 and a constant wind of $15 \mathrm{~m} \mathrm{~s}^{-1}$. The shape of the idealized mountain range (Schär et al., 2002) peaking at $1500 \mathrm{~m}$ for the central top was chosen to trigger the formation of several clouds. Simulations were run for $8 \mathrm{~h}$ with a time step of $4 \mathrm{~s}$. The results presented below are $1 \mathrm{~h}$ averages between 7 and $8 \mathrm{~h}$ of simulation.

The CCN population was composed of three modes, following Muhlbauer and Lohmann (2008, their Table 4). 


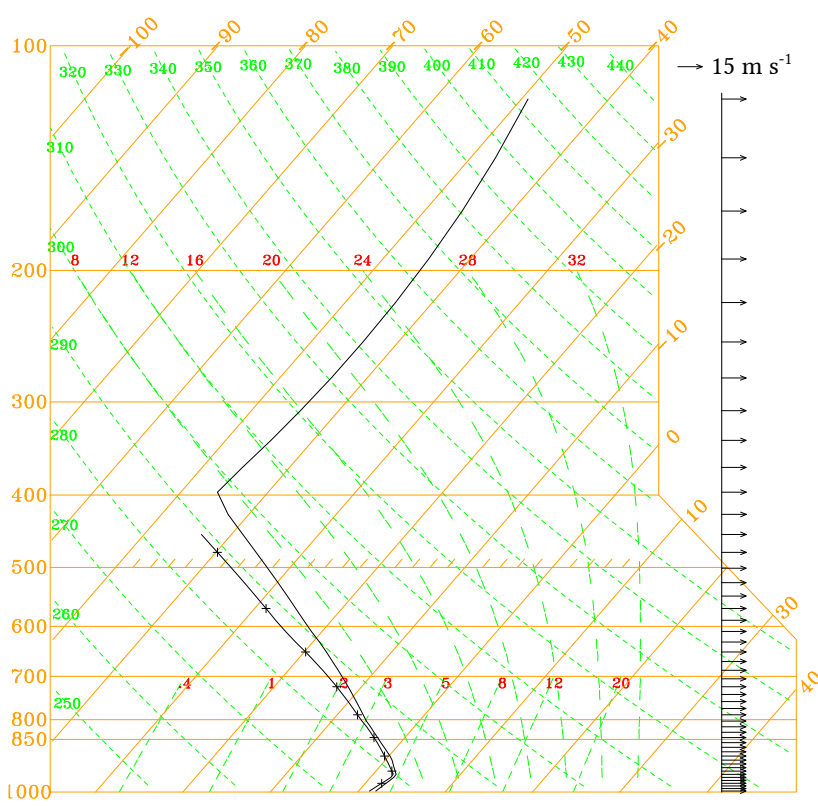

Figure 1. Reference sounding used to initialize the 2-D idealized simulations of orographic cold clouds.

This distribution was observed over the Swiss Alps during CLACE3 (Clouds and Aerosols Experiment). The concentrations of the three "sulfate" modes were set to 504, 618 and $0.35 \mathrm{~cm}^{-3}$ for the Aitken, accumulation and coarse modes, respectively, between the ground and $1000 \mathrm{~m}$ height. Above $1000 \mathrm{~m}$, the concentration decreased exponentially up to $10000 \mathrm{~m}$, where it reached the constant value of $0.01 \mathrm{~cm}^{-3}$. In the reference simulation, the IFN mode was composed of $60 \%$ of small dust particles, $1 \%$ of large dust particles, $33 \%$ of black carbon, and $6 \%$ of organics (size distribution parameters are shown in Table 1). The IFN concentration was homogeneous and was set to $100 \mathrm{~L}^{-1}$.

Other simulations were run with different IFN chemical compositions (single IFN type instead of the internally mixed reference case) keeping the same concentration, or with varying concentrations $\left(10,1000\right.$ and $\left.10000 \mathrm{~L}^{-1}\right)$ but keeping the IFN composition of the reference case. One simulation was run with the ice nucleation parameterization of Meyers et al. (1992), which does not depend on available IFN.

The pristine ice (colour shading) and activated IFN (colour contours) number concentrations of the reference experiment are shown in Fig. 2. At low levels high concentrations $\left(>1 \mathrm{~L}^{-1}\right)$ of pristine ice crystals are not locally associated with high concentrations of activated IFN, suggesting that these crystals were formed through the Hallett-Mossop process. At higher altitudes, pristine ice is mostly produced by IFN nucleation processes. Even then, pristine ice and activated IFN concentrations are more or less independent: when pristine ice grows into snow, the nucleated aerosols are definitively lost for the atmosphere, so fewer IFN are available downstream for locations where ice nucleation is pos-

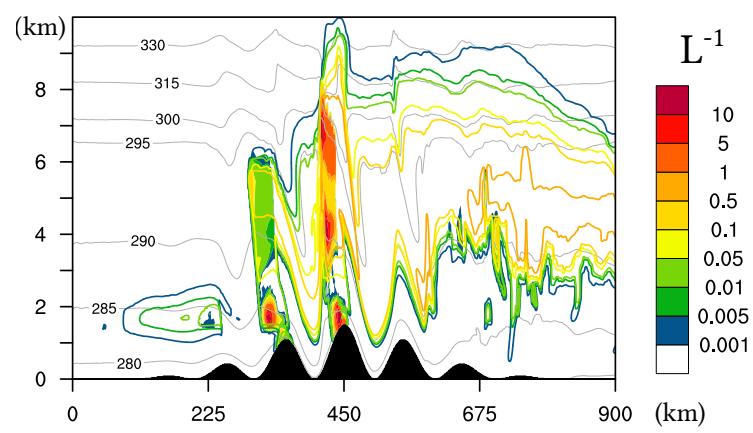

Figure 2. REF simulation of cold orographic clouds (1 h average between 7 and $8 \mathrm{~h}$ of simulation): number concentrations $\left(\mathrm{L}^{-1}\right)$ of the pristine ice (shading) and of the activated IFN (contours, same scale as the colour shading). The potential temperature (K) levels are superimposed and labelled.

sible. Recall that both free and activated IFN concentrations are transported along air parcel trajectories.

The pristine ice number concentrations shown in Fig. 3 refer to a simulation made with an initially large IFN concentration of $10000 \mathrm{~L}^{-1}$ (labelled "IFNx100"), and to another simulation labelled "MEYERS" and based on the ice nucleation parameterization of Meyers et al. (1992) to compute $N_{\mathrm{i}, X}^{*}(t)$, respectively. When compared to the previous reference simulation, the IFNx100 simulation produced many more ice crystals than expected. Interestingly, increasing the initial number concentration of IFN to $10000 \mathrm{~L}^{-1}$ in simulation IFNx100 (Fig. 3b) led to results similar to the MEYERS simulation (Fig. 3a). The same order of magnitude was noticed by Phillips et al. (2008) in their comparison with Meyers et al. (1992) to reach such levels of pristine ice number concentration. The number concentration of nucleated ice crystals in MEYERS is independent of the available IFN.

Figure 4 shows the vertical profiles of the mean pristine ice (a) number concentrations and (b) mixing ratios, and (c) the snow mixing ratios, of the three above-mentioned simulations and of four additional simulations made with a single mode of IFN. In these experiments the single IFN mode was alternately composed of pure organics $(\mathrm{O})$, black carbon (BC), small dust (DM1) or large dust (DM2), and was initialized with the same initial concentration as in the reference simulation. All the simulations show very similar pristine ice concentration and mixing ratio profiles below $2 \mathrm{~km}$ height. As previously stressed for the REF case, this is due to the dominant Hallett-Mossop secondary ice production process in this layer. Above, the impact of the initial IFN population shows up clearly. The $\mathrm{BC}$ and $\mathrm{O}$ simulations, with identical initial IFN concentration and size distribution, illustrate that black carbon is a more efficient nucleating agent than organics in the parameterization of Phillips et al. (2008). For IFN of identical composition and concentration, the biggest aerosols are also more efficiently nucleated (DM1 and DM2 simulations), as expected. As discussed above, the 

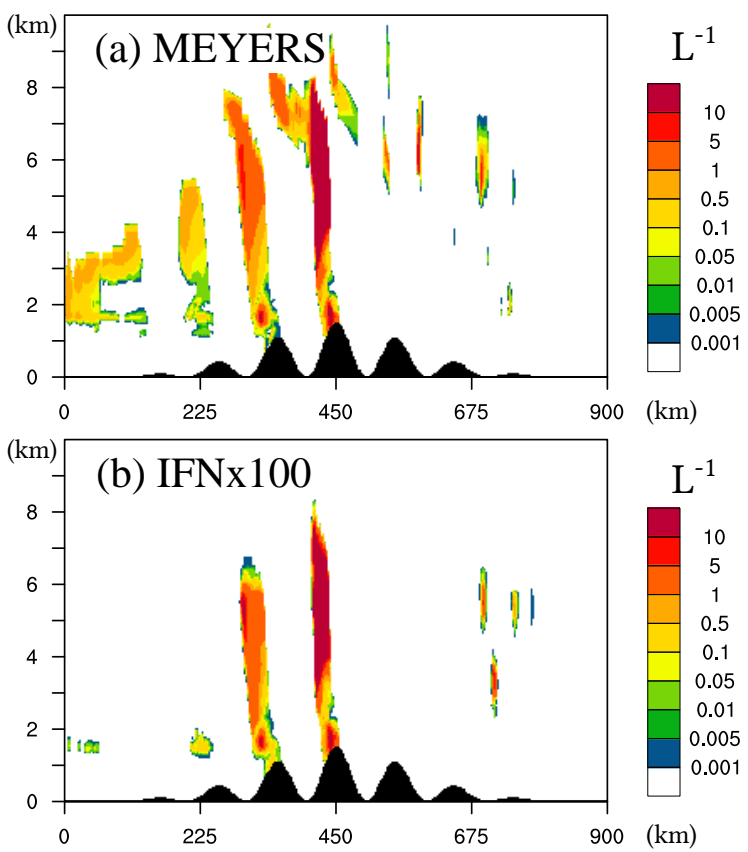

Figure 3. One-hour averaged pristine ice number concentration $\left(\mathrm{L}^{-1}\right)$ between 7 and $8 \mathrm{~h}$ of simulation for (a) the "MEYERS" and (b) "IFNx100" simulations of cold orographic clouds.

"IFNx100" simulation yields ice concentrations and mixing ratios comparable to MEYERS, up to an altitude of $6 \mathrm{~km}$. In contrast, all simulations led to very similar snow mixing ratio profiles (Fig. 4c). The explanation is that pristine ice is converted into snow/aggregate in the low levels where the deposition rate is high and according to the scheme described in Sect. 2.5.2. Once initiated, the snow/aggregate category of ice is transported upwards by the flow while simultaneously growing by water vapour deposition. For this specific case, the IFN concentration and composition seem to have little impact on the formation of precipitating ice. However, other cloud systems may respond differently to changes in IFN population, when heterogeneous nucleation operates at colder temperature. For instance, cirrus clouds are probably more sensitive to pristine ice number concentration to produce large crystals that precipitate in the form of virga.

In summary, Fig. 4 indicates that the IFN chemical composition and size distribution may have as great an impact as the initial IFN number concentration with the LIMA scheme. This is the major strength of Phillips et al. (2008, 2013)'s ice nucleation scheme allowing a sensitivity of the IFN to the particle size distribution and differentiating a nucleation efficiency according to the chemical nature of the IFN, after calibration.
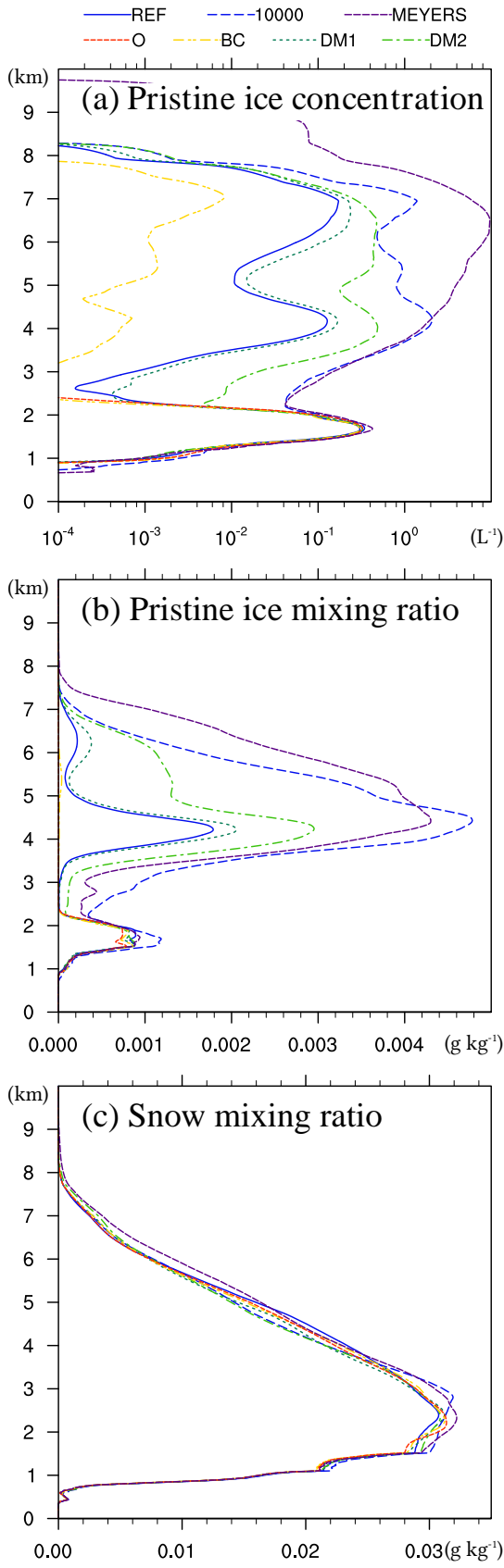

Figure 4. Mean vertical profiles ( $1 \mathrm{~h}$ horizontal averages between 7 and $8 \mathrm{~h}$ of simulation) of (a) the pristine ice number concentrations $\left(\mathrm{L}^{-1}\right)$, (b) the pristine ice mixing ratios $\left(\mathrm{g} \mathrm{kg}^{-1}\right)$ and (c) the snow/aggregate mixing ratios $\left(\mathrm{g} \mathrm{kg}^{-1}\right)$ for different simulations of cold orographic clouds. 

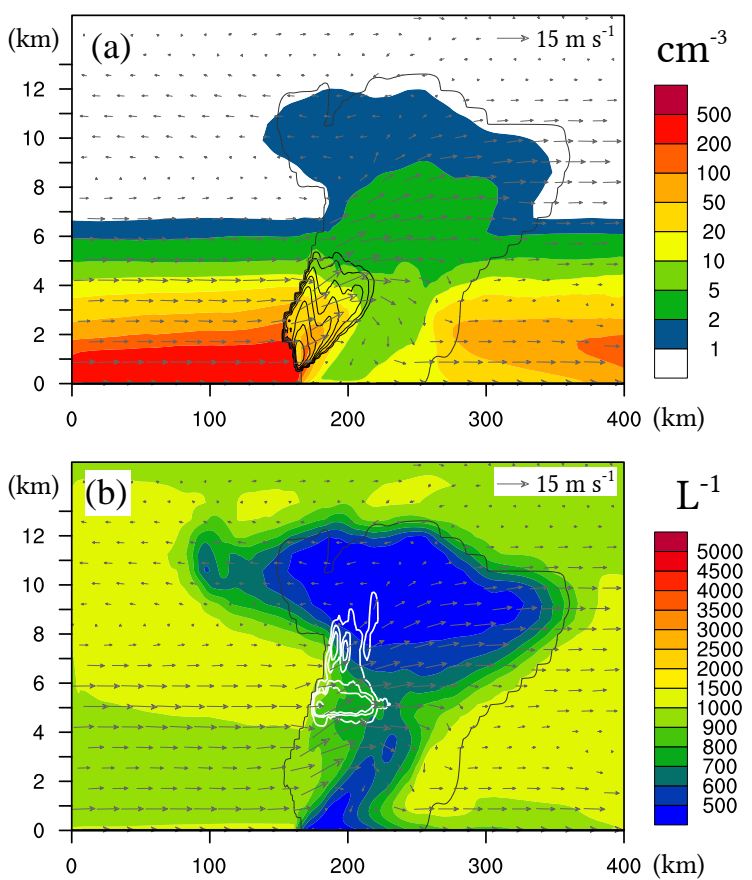

Figure 5. One-hour averages (between 7 and $8 \mathrm{~h}$ of simulation) of squall line characteristics of the REF experiment. (a) Free CCN (colours) and cloud droplet (black contours, same scale as free $\mathrm{CCN})$ number concentrations $\left(\mathrm{cm}^{-3}\right)$, and (b) free IFN (colours) and cloud ice (white contours at 0.01, 0.05, 0.1, 0.5, 1 and 5) number concentrations $\left(\mathrm{L}^{-1}\right)$. A single cloud contour (in grey at $10^{-6} \mathrm{~kg} \mathrm{~kg}^{-1}$ ) and the wind (vertical wind speed multiplied by 10 ) are superimposed.

Table 2. Background CCN configuration for the squall line idealized simulations.

\begin{tabular}{lccc}
\hline & $\begin{array}{c}\text { Aitken } \\
\text { mode }\end{array}$ & $\begin{array}{c}\text { Accumulation } \\
\text { mode }\end{array}$ & $\begin{array}{c}\text { Coarse } \\
\text { mode }\end{array}$ \\
\hline$N\left(\mathrm{~cm}^{-3}\right)$ & 300 & 140 & 50 \\
$d_{X}(\mu \mathrm{m})$ & 0.23 & 0.8 & 2.0 \\
$\sigma_{X}$ & 2.0 & 1.5 & 1.6 \\
\hline
\end{tabular}

\subsection{Sensitivity of mixed-phase convection to the aerosol population}

The 2-D idealized squall line test case (Caniaux et al., 1994; Berthet et al., 2010) was based on a squall line observed on 23 June 1981, during the Convection Profonde Tropicale (COPT, tropical deep convection) campaign. The domain had 320 points with a horizontal resolution of $1.25 \mathrm{~km}$, and 44 vertical levels. The simulations were run for $10 \mathrm{~h}$ with a time step of $2 \mathrm{~s}$. An artificial local cooling in the low levels, at a rate of $0.01 \mathrm{~K} \mathrm{~s}^{-1}$ for the first $10 \mathrm{~min}$, built up a cold pool to initiate convection.

In the reference simulation (REF), background $\mathrm{CCN}$ were represented by three modes with parameters taken from Chou

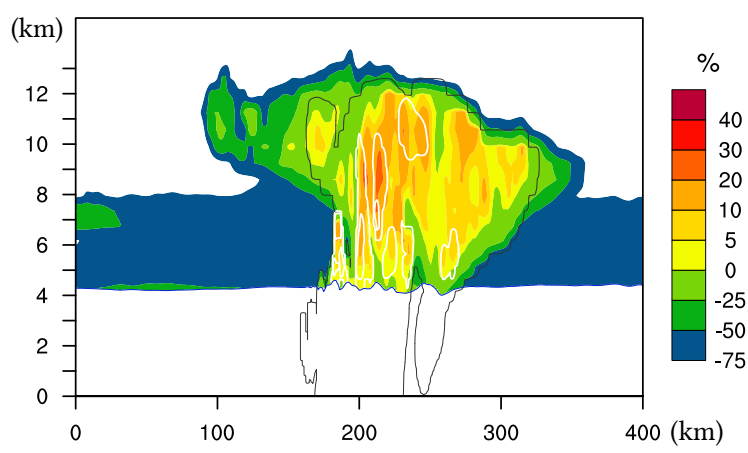

Figure 6. Instantaneous supersaturation over ice (colours, \%) and pristine ice concentration (white contours at $10^{-3}$ and $0.1 \mathrm{~L}^{-1}$ ) with cloud contour at $10^{-6} \mathrm{~kg} \mathrm{~kg}^{-1}$ (grey contour) and $0^{\circ} \mathrm{C}$ isotherm (blue contour), for the REF simulation of the squall line after $7 \mathrm{~h}$.

et al. (2008) and shown in Table 2. This distribution was observed in Niger during the AMMA campaign; it was taken as representative of sub-Sahelian aerosol conditions. The background $\mathrm{CCN}$ concentration was homogeneous between the ground and an altitude of $1 \mathrm{~km}$, with an exponential decay above up to $10 \mathrm{~km}$ height and a constant value of $0.01 \mathrm{~cm}^{-3}$. The background IFN mode was composed of $60 \%$ of small dust particles, $1 \%$ of large dust particles, $33 \%$ black carbon and $6 \%$ organics, with a homogeneous number concentration of $1000 \mathrm{~L}^{-1}$

Unless explicitly stated, figures for this case are $1 \mathrm{~h}$ averages between 7 and $8 \mathrm{~h}$ of simulation, once the squall line was well developed.

\subsubsection{Reference simulation}

Figure 5 shows the characteristics of the squall line in the mature stage. The mesoscale circulation is typical of a squall line with an upright ascent at the convergence of the moist inflow and the low-level cold-pool counterflow, a slow descent at the rear of the system, the return current associated with precipitations below the anvil, and a diverging flow at the top of the troposphere. Figure 5a highlights the high CCN concentrations ahead of the squall line in the low levels leading to a sharp contrast between the inflow region of the squall line and the return flow in the precipitating area. The CCN depletion is well marked where cloud droplets are forming. The CCN are also transported throughout the cloud system well above $10 \mathrm{~km}$ height. Concerning the IFN concentrations displayed in Fig. 5b, low concentrations are found between 6 and $12 \mathrm{~km}$ heights inside the squall line. Here the depletion is the result of the heterogeneous ice nucleation. The area of large concentrations of pristine ice crystals at $5 \mathrm{~km}$ height is explained by the secondary ice production (Hallett-Mossop) process. The reduced IFN concentrations in the lower, rainy regions (up to $4 \mathrm{~km}$ ) are mostly due to below-cloud scaveng- 
ing by rain which simultaneously affects the free $\mathrm{CCN}$ at the same location.

As emphasized previously, LIMA can sustain high supersaturations over cloud ice, but maintains a strict saturation level over the cloud droplets. The instantaneous supersaturation over ice above the $0^{\circ} \mathrm{C}$ isotherm after $7 \mathrm{~h}$ of simulation (Fig. 6) reaches $30 \%$ locally. So pristine ice crystals are formed very locally in vigorous ascents before being rapidly transformed into snow, mostly in the trailing stratiform region, and then into graupel, where supercooled water is available in the convective front.

\subsubsection{Sensitivity to the ice nucleation parameterization}

Vertical profiles of the pristine ice and snow mixing ratios are shown in Fig. 7, for the reference experiment (REF), for a simulation (MEYERS) using Meyers et al. (1991)'s ice nucleation parameterization, and for another simulation (CSTIFN) based on the LIMA scheme but with a "constant" IFN population. In CST-IFN, aerosols are initialized and transported in the same way as in REF, but the IFN are deliberately not depleted by ice nucleation, and therefore CST-IFN stands as the case of an infinite reservoir of aerosols. The vertical profiles in Fig. 7 are averages made over the stratiform part of the squall line where the rain rate is less than $5 \mathrm{~mm} \mathrm{~h}^{-1}$. They are shown for two periods of time between 5-6 and 7-8h. The REF and MEYERS simulations can be seen to evolve towards a similar cloud composition. The differences that were present in the early development of the squall line are reduced dramatically at the end of the simulations. In contrast, the CST-IFN case underlines the high sensitivity of the pristine ice mixing ratio to an inaccurate closure of the ice nucleation budget. Consequently, this suggests that the development of the pristine ice in the squall line is strongly limited by the IFN concentration. As for orographic cold cloud simulations, the ice mixing ratio in all simulations is mostly driven by a steady Hallett-Mossop process at around $6 \mathrm{~km}$ height.

The conversion of pristine ice crystals into snow/aggregates is size-dependent, and therefore a function of the concentration and of the mixing ratio of the small crystals. However, despite the large differences observed for the pristine ice, all the snow mixing ratio profiles tend to converge after $8 \mathrm{~h}$ (Fig. $7 \mathrm{c}$ and d). In the CST-IFN simulation, the snow mixing ratio grows faster during the storm development, but all simulations eventually reach a similar equilibrium. This suggests that the composition of the stratiform region in the mature stage of the squall line depends more on the storm environment, and that the complex interactions of snow/aggregates with other water condensate species (especially liquid water and graupel) tend to reach the same equilibrium despite different paths in cloud development.

\subsubsection{Sensitivity to aerosol loading}

A set of simulations were run with an additional aerosol mode, representing for instance the effect of fire emissions at the low levels, a dust outbreak at mid-level or a volcanic eruption in the upper troposphere. The composition of the aerosol plume was CCN, IFN, or coated IFN, with a homogeneous concentration $\left(10000 \mathrm{~L}^{-1}\right.$ for IFN and $1000 \mathrm{~cm}^{-3}$ for $\mathrm{CCN}$ and coated IFN plumes) in a given range of altitudes: 0-2 km for low-level plumes, 3-5 km for mid-level plumes, and $8-10 \mathrm{~km}$ for high-level plumes. A supplementary simulation was performed with background $\mathrm{CCN}$ as in REF, but with a homogeneous vertical number concentration, resulting in a similar CCN loading at low levels but a higher concentration above the boundary layer compared to REF.

Figure 8 shows a close view of the impact of the CCN population on the cloud droplets. The droplet number concentrations and mean droplet diameters are displayed for REF, simulations with a low-level and mid-level CCN plume (LOW$\mathrm{CCN}$ and MID-CCN, respectively) and in the case of a homogeneous initial $\mathrm{CCN}$ concentration (HOM-CCN). A lowlevel CCN plume directly feeding the convective updrafts increased the cloud droplet concentration and decreased their diameter. A mid-level plume or homogeneous CCN concentration had little impact in the lower part of the cloud (below $2 \mathrm{~km}$ ), but significantly changed the droplet population above with an increase in the supercooled droplet concentration and a larger extent of the cloudy region at the rear of the convective region.

The impact of an external plume of insoluble IFN on pristine ice concentration depended clearly on the altitude at which extra aerosols were injected, as illustrated in Fig. 9. The IFN in a low-level plume (LOW-IFN simulation) can be easily transported upwards and deeply inside the cloud system (Fig. 5a). This helps to maintain a high free IFN concentration during the mature stage compared to the REF case (Fig. 5b). These extra IFN yield a higher ice number concentration in the glaciated part of the cloud. In the opposite situation where additional IFN are brought by a high-level plume (HI-IFN simulation), they may have a strong impact during the development stage of the convection (the first $2 \mathrm{~h}$ of simulation, not shown). However, the impact of those IFN is much smaller during the mature stage of the squall line because of the detrainment of the air at the plume levels (Fig. 5b). This observation is also supported by the high similarity of the free IFN concentration below $6 \mathrm{~km}$ height in this case and the reference case. In any case, the concentration of pristine ice crystals was higher than in the REF simulation.

One-hour averages of cloud microphysics profiles of the REF case and of experiments rerun with an aerosol plume are shown in Fig. 10. The cloud droplet mixing ratios show that a CCN plume at mid-levels causes the greatest increase in the cloud water mixing ratio in the convective part. This MID$\mathrm{CCN}$ simulation also produced more supercooled droplets at higher altitudes. However, in the stratiform region, it was 
1-hour average at $6 \mathrm{~h}$
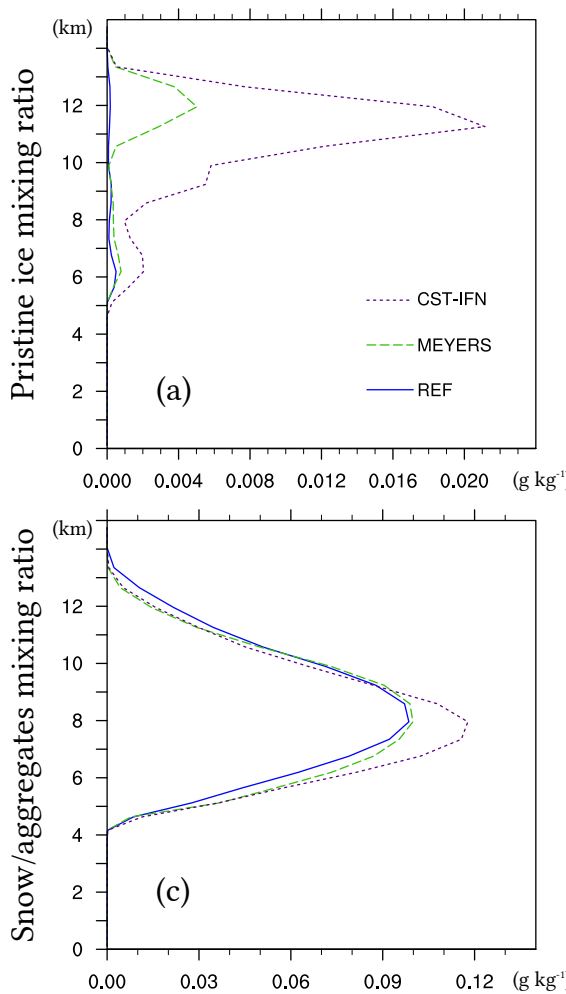

1-hour average at $8 \mathrm{~h}$
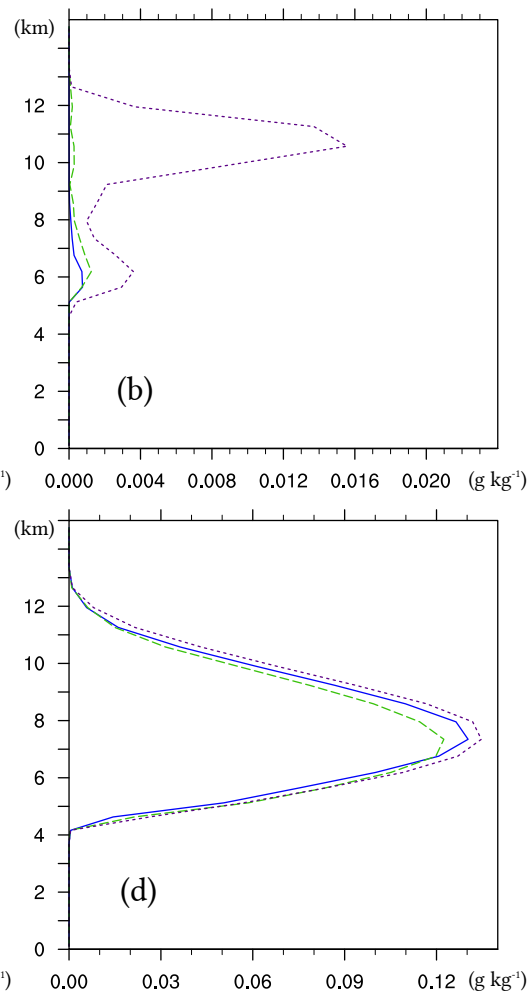

Figure 7. Mean vertical profiles ( $1 \mathrm{~h}$ horizontal averages) of cloud ice (top) and snow/aggregate (bottom) mixing ratios in the stratiform part of the cloud $\left(\mathrm{g} \mathrm{kg}^{-1}\right)$ for simulations REF, MEYERS and CST-IFN. The profiles are averaged between 5-6h (left) and 7-8 $\mathrm{h}$ (right).

the LOW-CCN plume that had the most influence on the cloud droplet mixing ratio. An explanation is that the midlevel CCN plume is less sensitive to below-cloud scavenging, while the low-level CCN plume is the best configuration to transport the droplets to the stratiform part of the squall line along the slow mesoscale ascent of the squall line. The profiles in Fig. 10a and b show that changes in the IFN population have a modest impact on the mean cloud water. This contrasts with the sensitivity of the precipitating water development to both the $\mathrm{CCN}$ and IFN populations (Fig. 10c). For instance, lower rain water mixing ratios were obtained for MID-CCN and LOW-CCN simulations because the cloud droplet autoconversion efficiency was less when the droplet size was reduced. For these simulations, the concavity of the rain profiles was the result of the enhancement of the warm microphysical processes i.e. the growth of the raindrops by accretion of the cloud droplets below $3 \mathrm{~km}$ height. The three simulations with perturbed IFN concentrations also produced different rain mixing ratios. However, despite large differences in rain profiles, all simulations produce similar amounts of rain at ground level.

The pristine ice mixing ratio in the convective part of the cloud also showed large variations depending on the population of aerosols, when either $\mathrm{CCN}$ or IFN concentrations were increased (Fig. 10d). With an aerosol plume, the inter- actions between the warm and cold phases at slightly negative temperatures were enhanced. Hence the Hallett-Mossop process was more efficient when more graupel particles were produced and more cloud droplets were available for collection. The pristine ice production at higher altitudes was also impacted, although during the interval of time (between 7 and $8 \mathrm{~h}$ of simulation) most of the initial pristine ice had already converted into snow. The snow/aggregate profiles in Fig. 10e do not vary very much between the simulations. The perturbed high IFN plume case maximizes the snow/aggregate mixing ratio, while LOW-CCN and MID$\mathrm{CCN}$ simulations produce less snow, due to the more important conversion of snow into graupel. The graupel profiles showed some variability (Fig. 10f). The simulations with a CCN plume produced much graupel because of the enhanced riming processes. The graupel profiles were also enhanced in the case of IFN plume at high levels (as for the $\mathrm{CCN}$ cases) compared to the REF simulation. A comparison of the rain and graupel mean profiles (Fig. 10d and f, respectively) shows that the melting of the graupel particles cannot explain the raindrop profiles and that a contribution of the warm processes (raindrop growth at the expense of the cloud droplets below the freezing level) is meaningful.

The vertical profiles of the pristine ice number concentration, using a $1 \mathrm{~h}$ average on the horizontal, are shown in 

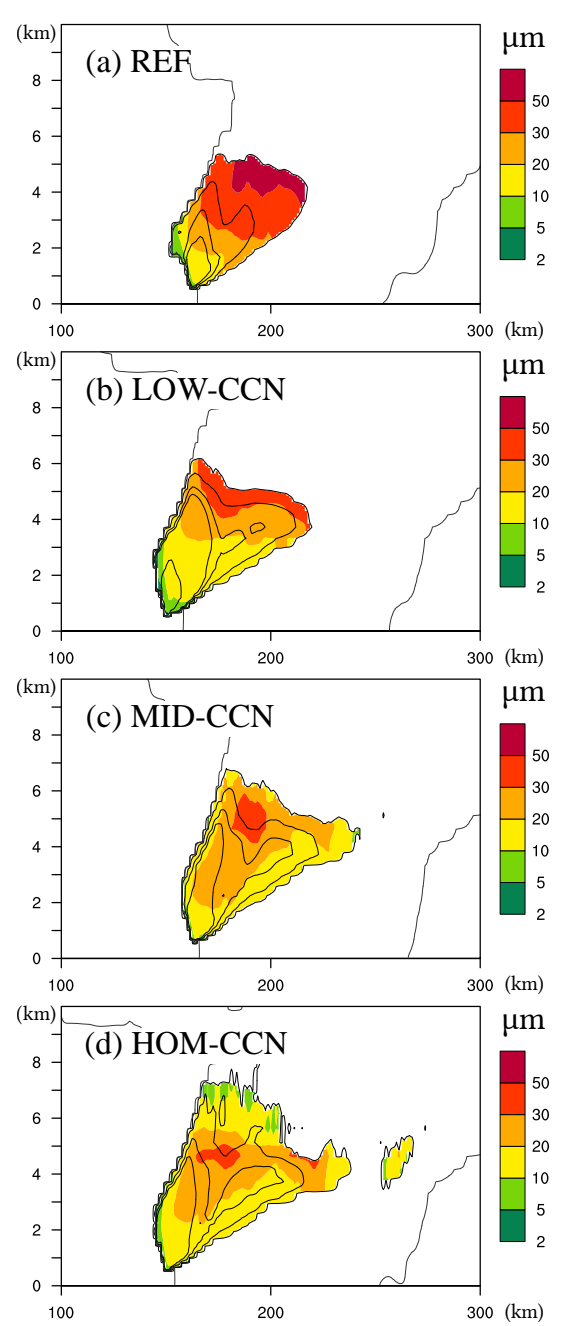

Figure 8. One-hour averages (between 7 and $8 \mathrm{~h}$ of simulation) of the equivalent cloud droplet diameter ( $\mu \mathrm{m}$, colours), cloud droplet number concentration (black contours at 1, 10, 50, 100 and $500 \mathrm{~cm}^{-3}$ ), and cloud contour at $10^{-6} \mathrm{~kg} \mathrm{~kg}^{-1}$ (grey contour), for the (a) REF, (b) LOW-CCN, and (c) MID-CCN simulations, and (d) a simulation with homogeneous initial $\mathrm{CCN}$ profiles.

Fig. 11 for REF, MEYERS and CST-IFN and for the three simulation cases with an IFN plume. Simulations made with the plume significantly increase the ice concentration at altitudes up to $11 \mathrm{~km}$, but none of them reproduces the peak simulated by MEYERS above. The CST-IFN simulation gave an even higher ice concentration. This suggests that the high pristine ice concentrations found with MEYERS between 11 and $13 \mathrm{~km}$ are due to the "infinite reservoir" effect of the MEYERS scheme which does not take the reality of IFN depletion after heterogeneous nucleation into account.

The last Fig. 12 shows the $8 \mathrm{~h}$ accumulated precipitation of various squall line simulations. It is interesting to note that, despite some marked differences found in both cloud structure and dynamics, changes in the aerosol population do not dramatically affect the precipitation amounts (even for the
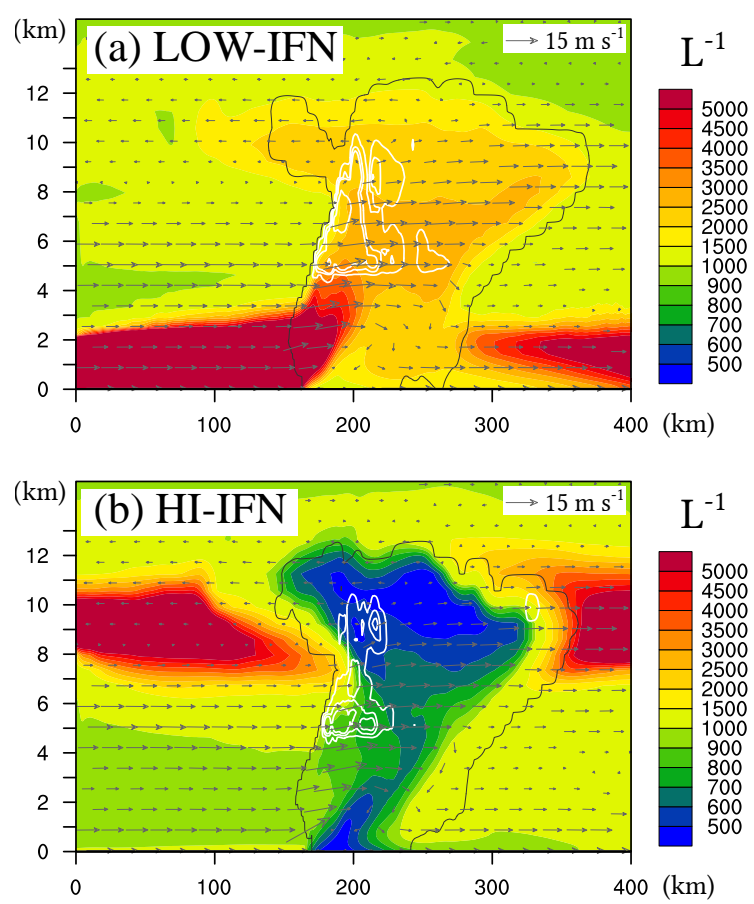

Figure 9. Same as Fig. 5 b but for (a) LOW-IFN and (b) HI-IFN simulations.

MEYERS case). Because of the complex aerosol-cloud interactions and in-cloud microphysics retroactions, no definitive conclusion can be drawn regarding the impact of higher aerosol concentrations on precipitation (intensity and location).

\section{Summary and perspectives}

A quasi two-moment, mixed-phase microphysical scheme, called LIMA, was developed in the Meso-NH mesoscale research model, with a special focus on aerosol-cloud interactions, especially through the $\mathrm{CCN}$ activation process (an extension of the Cohard et al., 1998 scheme) and the IFN nucleation processes (adapted from the empirical scheme of Phillips et al., 2008, 2013). The two-moment representation of the cloud droplets, raindrops and pristine ice crystals was improved through a multimodal approach, the aerosol population serving as CCN and/or IFN, depending on their solubility. The budget equation of each aerosol mode (resolved and turbulent transport, below-cloud scavenging, replenishment by cloud droplet evaporation and ice crystal sublimation) allowed the best estimate of the number concentration of the free (available) aerosols to be made at locations where activation and nucleation may occur.

The comprehensive treatment of the warm-phase processes follows Cohard and Pinty (2000a). The assumption of water vapour saturation over the cloud droplets is made. This scheme of implicit adjustment to saturation is reinforced 

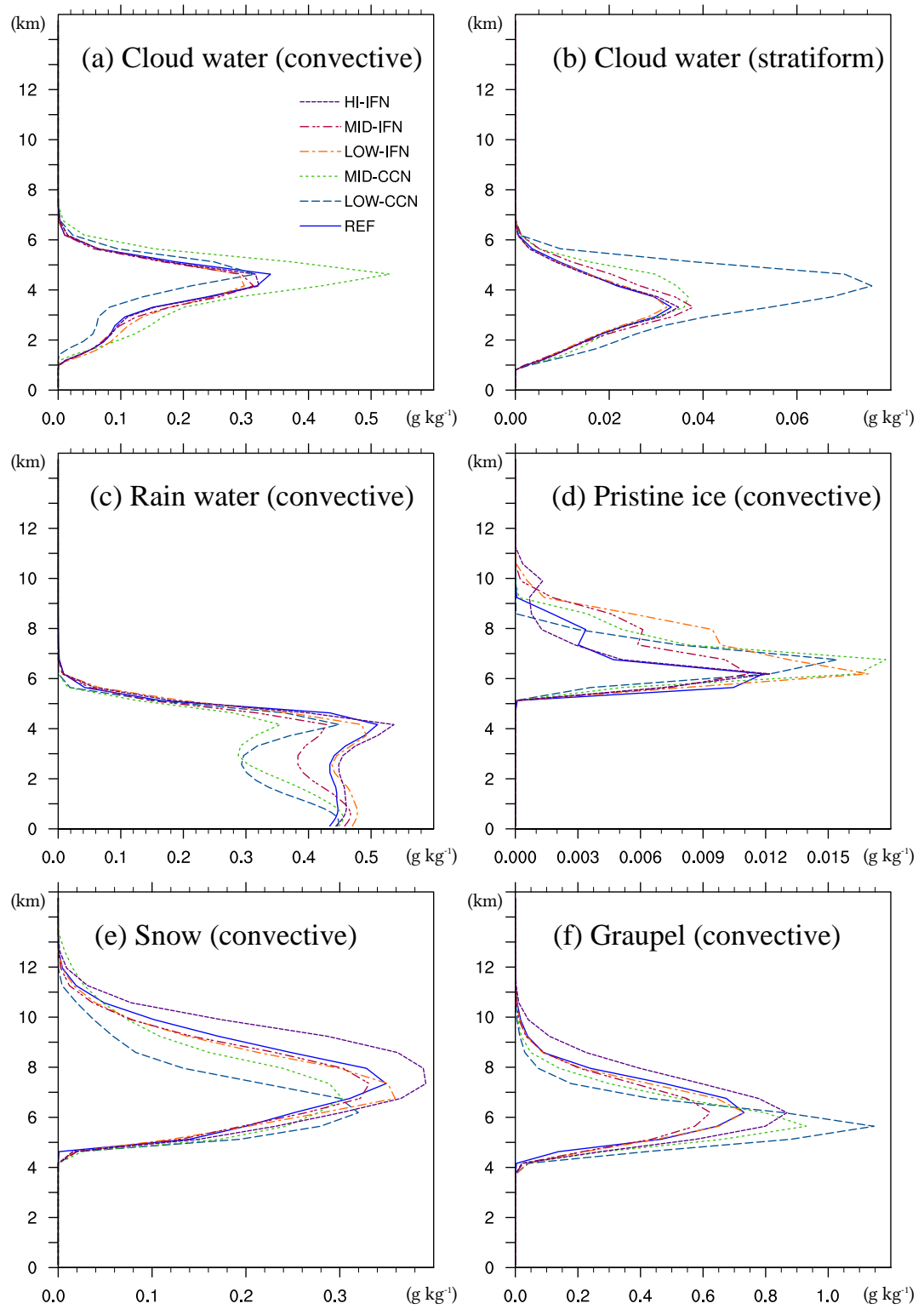

Figure 10. Mean vertical profiles ( $1 \mathrm{~h}$ horizontal averages between 7 and $8 \mathrm{~h}$ of simulation) of the cloud water mixing ratio ( $\left.\mathrm{g} \mathrm{kg}^{-1}\right)$ of (a) the convective and (b) the stratiform part of the squall line and the mean profiles of (c) the rain water, (d) the cloud ice, (e) the snow/aggregate and (f) the graupel mixing ratios $\left(\mathrm{g} \mathrm{kg}^{-1}\right)$ of the convective part of the squall line. The curves correspond to the REF experiment and simulations to an additional aerosol plume.

by the parameterization of a subgrid supersaturation peak to compute the CCN activation rate in the spirit of Köhler theory. In the cold phase, the pristine ice crystals can form by heterogeneous nucleation on a wide variety of IFN (condensation/deposition, contact and immersion involving coated or partially soluble IFN), by homogeneous freezing of the cloud droplets and $\mathrm{CCN}$ and by the Hallett-Mossop ice multiplication process. All these processes are very dependent on the temperature and supersaturation conditions. The growth of ice crystals by water vapour deposition is treated explicitly (deposition rate) so that the field of wa- ter vapour can evolve freely. This situation can lead to large supersaturations over ice that can reach $\sim 40 \%$ in convective regions. The growth of the largest pristine crystals is computed solely as a bulk transfer rate of the pristine ice to the "snow-aggregate" category of precipitating ice, following the idea of Harrington et al. (1995). As there is much more uncertainty in processes involving precipitating ice species (currently "snow/aggregate" and "graupel/frozen drops" categories in LIMA) combined with the wide variety of shapes and ice particle properties, a single-moment representation of the "snow" and "graupel" species was felt to be a good com- 

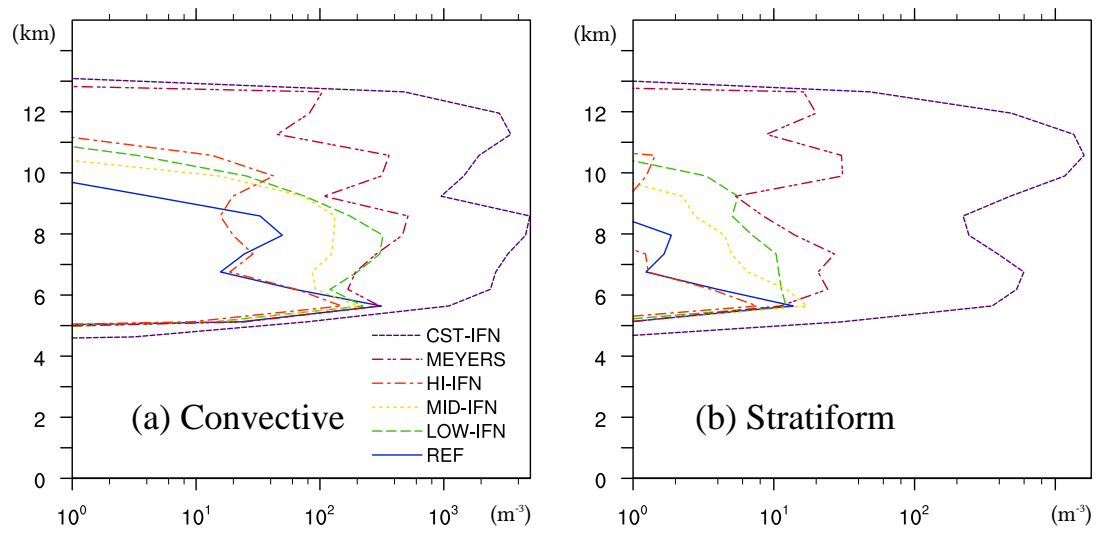

Figure 11. Mean vertical profiles ( $1 \mathrm{~h}$ horizontal averages between 7 and $8 \mathrm{~h}$ of simulation) of pristine ice number concentration $\left(\mathrm{m}^{-3}\right)$ in (a) the convective and (b) the stratiform part of the squall line for MEYERS, REF, CST-IFN and three simulations with an IFN plume.

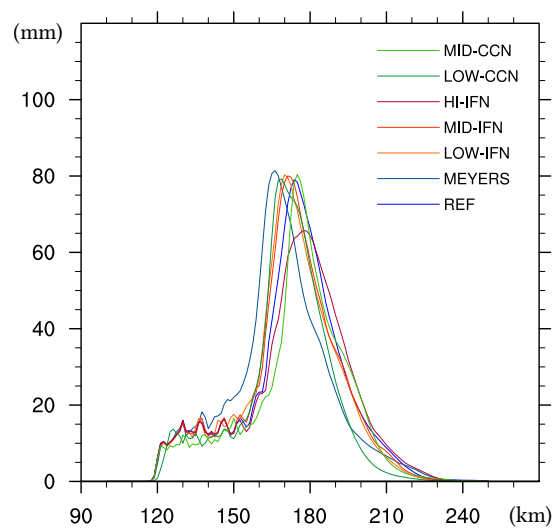

Figure 12. $8 \mathrm{~h}$ accumulated precipitation $(\mathrm{mm})$ for different squall line simulations.

promise. The "snow/aggregate" category grows by pristine ice crystal aggregation and by light riming of supercooled cloud droplets and raindrops. The conversion of this particle category into "graupel" depends on the critical size (droplet riming) or critical density (raindrop riming) of the aggregate particle. The dry and wet growth modes of the "graupel/frozen drops" are considered (Pinty and Jabouille, 1998; Lascaux et al., 2006) with an option to isolate "hail" as a full category of precipitating ice or keep it combined with graupel. In any case, hail is formed when graupel grows in the wet growth mode.

The capabilities of LIMA were illustrated for two idealized 2-D cases, designed to highlight the behaviour of the scheme in the case of cold- and mixed-phase clouds. As expected, the microstructure of cold orographic clouds responded to the IFN type, size distribution and initial concentration. The budget of the free and nucleated IFN is essential to limit the nucleating process downwind of a series of clouds. A comparison between the empirical, but calibrated, parameterization of Phillips et al. (2008) and the widely used formula of Meyers et al. (1997) shows that high IFN concentrations $\left(\sim 10000 \mathrm{~L}^{-1}\right)$ are necessary to obtain similar results. A 2-D squall line test case was studied to show the importance of the free $\mathrm{CCN}$ and IFN transport in an organized system, in spite of aerosol depletion (1) by in-cloud activation and nucleation and, (2) to a lower degree, by belowcloud scavenging. Simulations were performed for a reference case and after adding a plume of $\mathrm{CCN}$ or IFN placed in different layers of the atmosphere. The results show that the concentrations of the cloud droplets and the pristine ice crystals respond well to the plume content and to its vertical location.

The next improvement to be made to the LIMA scheme concerns a shape differentiation of the pristine ice crystals. The crystal shape is a useful tracer with an impact on deposition (crystal capacitance), on sedimentation rates (crystal aerodynamic properties) and on cloud radiative transfer (crystal optical scattering properties). However, the most promising use of the LIMA scheme is in the simulation of 3-D meteorological situations with a full initialization of the aerosol fields. Here the strategy is based on aerosol analyses provided by the MACC project (http://www. gmes-atmosphere.eu/) for initial aerosol loading and for lateral boundary forcing in case of inflow conditions. Vié and Pinty (2014) presented the first results of a heavy precipitating convective system observed over south-eastern France in September 2012. This coupling strategy, together with its calibration and the validation of LIMA using data collected during the HyMeX (http://www.hymex.org) Special Observing Period, is still a work in progress and will be presented in a forthcoming paper. 
Appendix A: Integration of the activable IFN number concentration

To integrate Eq. (16), and compute the number concentration of activable IFN, two methods are used, depending on the temperature of the surroundings.

\section{A1 For temperatures warmer than $-35^{\circ} \mathrm{C}$}

In this case, the fraction of frozen IFN remains small, thus the approximation $\mu_{X} \ll 1$ can be made. Using the Taylor series $\exp (-X) \simeq 1-X+o\left(X^{2}\right)$, Eq. (16) becomes

$N_{\mathrm{i}, X}^{*} \simeq \int_{0.1 \mu \mathrm{m}}^{\infty} \mu_{X}\left(d_{a}, S_{\mathrm{i}}, T\right) \frac{\mathrm{d} N_{X}}{\mathrm{~d} d_{a}} \mathrm{~d} d_{a}$.

Let us define $A\left(S_{\mathrm{i}}, T\right)=H_{X}\left(S_{\mathrm{i}}, T\right) \xi(T)\left[\frac{\alpha_{X} N_{\mathrm{i}, \text { ref }}}{\Omega_{X, \text { ref }}}\right]$. Equation (17) becomes

$\mu_{X}\left(d_{a}, S_{\mathrm{i}}, T\right)=A\left(S_{\mathrm{i}}, T\right) \frac{\mathrm{d} \Omega_{X}}{\mathrm{~d} N_{X}}$,

$\mu_{X}\left(d_{a}, S_{\mathrm{i}}, T\right) \simeq A\left(S_{\mathrm{i}}, T\right) \pi d_{a}^{2}$.

Then, with $n\left(d_{a}\right)$ as defined in Eq. (1),

$$
\begin{aligned}
N_{\mathrm{i}, X}^{*} \simeq & A\left(S_{\mathrm{i}}, T\right) \pi\left(N_{\text {free }}+N_{\text {nucl }}\right) \int_{0.1}^{\infty} d_{a}^{2} n\left(d_{a}\right) \mathrm{d} d_{a} \\
\simeq & A\left(S_{\mathrm{i}}, T\right) \pi\left(N_{\text {free }}+N_{\text {nucl }}\right) \\
& \left(M_{2}-\int_{0}^{0.1} d_{a}^{2} n\left(d_{a}\right) \mathrm{d} d_{a}\right)
\end{aligned}
$$

with $M_{2}=d_{X}^{2} e^{\left(\sqrt{2} \ln \left(\sigma_{X}\right)\right)^{2}}$ the second moment of the lognormal distribution (Tripoli et al., 1988). Using two successive variable changes in the remaining integral, and the definition of the error function, we have

$$
\begin{aligned}
N_{\mathrm{i}, X}^{*} \simeq & A\left(S_{\mathrm{i}}, T\right) \pi\left(N_{\text {free }}+N_{\text {nucl }}\right) \frac{d_{X}^{2} e^{\left(\sqrt{2} \ln \left(\sigma_{X}\right)\right)^{2}}}{2} \\
& \times\left[1+\operatorname{erf}\left(\sqrt{2} \ln \left(\sigma_{X}\right)-\frac{\ln \left(0.1 \mu \mathrm{m} / d_{X}\right)}{\sqrt{2} \ln \left(\sigma_{X}\right)}\right)\right] .
\end{aligned}
$$

\section{A2 For temperatures colder than $-35^{\circ} \mathrm{C}$}

Here, the previous approximation is no longer valid and Eq. (16) is rewritten as

$$
\begin{aligned}
N_{\mathrm{i}, X}^{*}= & \int_{0}^{\infty}\left\{1-\exp \left[-\mu_{X}\left(d_{a}, S_{\mathrm{i}}, T\right)\right]\right\} \frac{\mathrm{d} N_{X}}{\mathrm{~d} d_{a}} \mathrm{~d} d_{a} \\
& -\int_{0}^{0.1 \mu \mathrm{m}}\left\{1-\exp \left[-\mu_{X}\left(d_{a}, S_{\mathrm{i}}, T\right)\right]\right\} \frac{\mathrm{d} N_{X}}{\mathrm{~d} d_{a}} \mathrm{~d} d_{a} .
\end{aligned}
$$

A Gauss-Hermite quadrature is used to compute the first term of this expression. Integration of the second term is simplified assuming that $d_{X} \ll 1 \mu \mathrm{m}$, which allows us to use the same method as described in Appendix A1. 


\section{The Supplement related to this article is available online at doi:10.5194/gmd-9-567-2016-supplement.}

Acknowledgements. J.-P. Pinty wishes to warmly thank V. Phillips for fruitful discussions about the nucleation scheme and for the availability of the original code. B. Vié thanks Météo-France for supporting a 1-year secondment at Laboratoire d'Aérologie. Susan Becker corrected the English of the manuscript. Computations were performed on the 36-node cluster of Lab. d'Aérologie. J.-P. Pinty acknowledges CALMIP (CALcul en MIdi-Pyrénées) of the University of Toulouse for access to the former hyperion and eos supercomputers where useful additional simulations could be performed. The authors thank the three anonymous reviewers who helped to improve the manuscript.

Edited by: J. Williams

\section{References}

ACPC: Aerosols, Clouds, Precipitation and Climate, Steering Committee: Science Plan and Implementation Strategy, Tech. rep., IGAC (International Global Atmospheric Chemistry), Boulder, available at: http://www.igacproject.org/sites/all/themes/ bluemasters/images/2009_ACPC_SciencePlan_FINAL.pdf (last access: 2 September 2015), 2009.

Albrecht, B. A.: Aerosols, cloud microphysics, and fractional cloudiness, Science, 245, 1227-1230, 1989.

Andreae, M. O., Rosenfeld, D., Artaxo, P., Costa, A., Frank, G., Longo, K., and Silva-Dias, M.: Smoking rain clouds over the Amazon, Science, 303, 1337-1342, 2004.

Aouizerats, B., Thouron, O., Tulet, P., Mallet, M., Gomes, L., and Henzing, J. S.: Development of an online radiative module for the computation of aerosol optical properties in 3-D atmospheric models: validation during the EUCAARI campaign, Geosci. Model Dev., 3, 553-564, doi:10.5194/gmd-3-553-2010, 2010.

Barahona, D. and Nenes, A.: Parameterizing the competition between homogeneous and heterogeneous freezing in ice cloud formation - polydisperse ice nuclei, Atmos. Chem. Phys., 9, 59335948, doi:10.5194/acp-9-5933-2009, 2009.

Beheng, K. D.: Microphysical properties of glaciating cumulus clouds: comparison of measurements with a numerical simulation, Q. J. Roy. Meteor. Soc., 113, 1377-1382, doi:10.1002/qj.49711347815, 1987.

Berry, E. X. and Reinhardt, R. L.: An analysis of cloud drop growth by collection Part II. Single initial distributions, J. Atmos. Sci., 31, 1825-1831, 1974.

Berthet, S., Leriche, M., Pinty, J.-P., Cuesta, J., and Pigeon, G.: Scavenging of aerosol particles by rain in a cloud resolving model, Atmos. Res., 96, 325-336, 2010.

Caniaux, G., Redelsperger, J., and Lafore, J.: A numerical study of the stratiform region of a fast-moving squall line. Part I: General description and water and heat budgets, J. Atmos. Sci., 51, 20462074, 1994.
Chou, C., Formenti, P., Maille, M., Ausset, P., Helas, G., Harrison, M., and Osborne, S.: Size distribution, shape, and composition of mineral dust aerosols collected during the African Monsoon Multidisciplinary Analysis Special Observation Period 0: dust and biomass-burning experiment field campaign in Niger, January 2006, J. Geophys. Res.-Atmos., 113, D00C10, doi:10.1029/2008JD009897, 2008.

Cohard, J.-M. and Pinty, J.-P.: A comprehensive two-moment warm microphysical bulk scheme. I: Description and tests, Q. J. Roy. Meteor. Soc., 126, 1815-1842, doi:10.1002/qj.49712656613, 2000a.

Cohard, J.-M. and Pinty, J.-P.: A comprehensive two-moment warm microphysical bulk scheme. II: 2D experiments with a nonhydrostatic model, Q. J. Roy. Meteor. Soc., 126, 1843-1859, doi:10.1002/qj.49712656614, 2000 b.

Cohard, J.-M., Pinty, J.-P., and Bedos, C.: Extending Twomey’s analytical estimate of nucleated cloud droplet concentrations from CCN spectra, J. Atmos. Sci., 55, 3348-3357, 1998.

Cohard, J.-M., Pinty, J.-P., and Suhre, K.: On the parameterization of activation spectra from cloud condensation nuclei microphysical properties, J. Geophys. Res.-Atmos., 105, 1175311766, doi:10.1029/1999JD901195, 2000.

DeMott, P., Prenni, A., Liu, X., Kreidenweis, S., Petters, M., Twohy, C., Richardson, M., Eidhammer, T., and Rogers, D.: Predicting global atmospheric ice nuclei distributions and their impacts on climate, P. Natl. Acad. Sci. USA, 107, 11217-11222, 2010.

Diehl, K. and Wurzler, S.: Heterogeneous drop freezing in the immersion mode: model calculations considering soluble and insoluble particles in the drops, J. Atmos. Sci., 61, 2063-2072, 2004.

Ferek, R. J., Garrett, T., Hobbs, P. V., Strader, S., Johnson, D., Taylor, J. P., Nielsen, K., Ackerman, A. S., Kogan, Y., Liu, Q., Albrecht, B. A., and Babb, D.: Drizzle suppression in ship tracks, J. Atmos. Sci., 57, 2707-2728, 2000.

Fouquart, Y. and Bonnel, B.: Computations of solar heating of the earth's atmosphere - a new parameterization, Beitraege zur Physik der Atmosphaere, 53, 35-62, 1980.

Geoffroy, O., Brenguier, J.-L., and Sandu, I.: Relationship between drizzle rate, liquid water path and droplet concentration at the scale of a stratocumulus cloud system, Atmos. Chem. Phys., 8, 4641-4654, doi:10.5194/acp-8-4641-2008, 2008.

Gilmore, M. S. and Straka, J. M.: The Berry and Reinhardt autoconversion parameterization: a digest, J. Appl. Meteorol. Clim., 47, 375-396, 2008.

Hallett, J. and Mossop, S. C.: Production of secondary ice particles during the riming process, Nature, 249, 26-28, doi:10.1038/249026a0, 1974.

Harrington, J. Y., Meyers, M. P., Walko, R. L., and Cotton, W. R.: Parameterization of ice crystal conversion processes due to vapor deposition for mesoscale models using double-moment basis functions. Part I: Basic formulation and parcel model results, J. Atmos. Sci., 52, 4344-4366, doi:10.1175/15200469(1995)052<4344:POICCP>2.0.CO;2, 1995.

Johnson, B., Shine, K., and Forster, P.: The semi-direct aerosol effect: impact of absorbing aerosols on marine stratocumulus, Q. J. Roy. Meteor. Soc., 130, 1407-1422, 2004.

Kärcher, B. and Lohmann, U.: A parameterization of cirrus cloud formation: homogeneous freezing of supercooled 
aerosols, J. Geophys. Res.-Atmos., 107, AAC4.1-AAC4.10, doi:10.1029/2001JD000470, 2002.

Khairoutdinov, M. and Kogan, Y.: A new cloud physics parameterization in a large-eddy simulation model of marine stratocumulus, Mon. Weather Rev., 128, 229-243, 2000.

Khvorostyanov, V. I. and Curry, J. A.: The theory of ice nucleation by heterogeneous freezing of deliquescent mixed CC N. Part I: Critical radius, energy, and nucleation rate, J. Atmos. Sci., 61, 2676-2691, 2004.

Kogan, Y.: A cumulus cloud microphysics parameterization for cloud-resolving models, J. Atmos. Sci., 70, 1423-1436, 2013.

Lafore, J. P., Stein, J., Asencio, N., Bougeault, P., Ducrocq, V., Duron, J., Fischer, C., Héreil, P., Mascart, P., Masson, V., Pinty, J. P., Redelsperger, J. L., Richard, E., and Vilà-Guerau de Arellano, J.: The Meso-NH Atmospheric Simulation System. Part I: adiabatic formulation and control simulations, Ann. Geophys., 16, 90-109, doi:10.1007/s00585-997-0090-6, 1998.

Lascaux, F., Richard, E., and Pinty, J.-P.: Numerical simulations of three different MAP IOPs and the associated microphysical processes, Q. J. Roy. Meteor. Soc., 132, 1907-1926, 2006.

Lebo, Z. J. and Morrison, H.: A novel Scheme for parameterizing aerosol processing in warm clouds, J. Atmos. Sci., 70, 35763598, 2013.

Lim, K.-S. S. and Hong, S.-Y.: Development of an effective doublemoment cloud microphysics scheme with prognostic cloud condensation nuclei $(\mathrm{CCN})$ for weather and climate models, Mon. Weather Rev., 138, 1587-1612, 2010.

Long, A. B.: Solutions to the droplet collection equation for polynomial kernels, J. Atmos. Sci., 31, 1040-1052, 1974.

Meyers, M. P., DeMott, P. J., and Cotton, W. R.: New primary icenucleation parameterizations in an explicit cloud model, J. Appl. Meteorol., 31, 708-721, 1992.

Meyers, M. P., Walko, R. L., Harrington, J. Y., and Cotton, W. R.: New RAMS cloud microphysics parameterization. Part II: The two-moment scheme, Atmos. Res., 45, 3-39, 1997.

Milbrandt, J. and Yau, M.: A multimoment bulk microphysics parameterization. Part I: Analysis of the role of the spectral shape parameter, J. Atmos. Sci., 62, 3051-3064, 2005 a.

Milbrandt, J. and Yau, M.: A multimoment bulk microphysics parameterization. Part II: A proposed three-moment closure and scheme description, J. Atmos. Sci., 62, 3065-3081, 2005b.

Mlawer, E. J., Taubman, S. J., Brown, P. D., Iacono, M. J., and Clough, S. A.: Radiative transfer for inhomogeneous atmospheres: RRTM, a validated correlated-k model for the longwave, J. Geophys. Res.-Atmos., 102, 16663-16682, 1997.

Morrison, H. and Grabowski, W. W.: Comparison of bulk and bin warm-rain microphysics models using a kinematic framework, J. Atmos. Sci., 64, 2839-2861, 2007.

Morrison, H. and Grabowski, W. W.: A novel approach for representing ice microphysics in models: description and tests using a kinematic framework, J. Atmos. Sci., 65, 1528-1548, 2008.

Morrison, H., Curry, J., and Khvorostyanov, V.: A new doublemoment microphysics parameterization for application in cloud and climate models. Part I: Description, J. Atmos. Sci., 62, 16651677, 2005.

Morrison, H., Thompson, G., and Tatarskii, V.: Impact of cloud microphysics on the development of trailing stratiform precipitation in a simulated squall line: comparison of one-and two-moment schemes, Mon. Weather Rev., 137, 991-1007, 2009.
Muhlbauer, A. and Lohmann, U.: Orographic mixed-phase stratiform cloud case, in: WMO Cloud Modeling Workshop, Cozumel, Mexico, 14-17 July 2008, available at: http://www.rap. ucar.edu/ gthompsn/workshop2008/case1_description.pdf (last access: 2 September 2015), 1-22, 2008.

Muhlbauer, A., Grabowski, W. W., Malinowski, S. P., Ackerman, T. P., Bryan, G. H., Lebo, Z. J., Milbrandt, J. A., Morrison, H., Ovchinnikov, M., Tessendorf, S., Thériault, J. M., and Thompson, G.: Reexamination of the state of the art of cloud modeling shows real improvements, B. Am. Meteorol. Soc., 94, ES45ES48, 2013.

Niedermeier, D., Shaw, R. A., Hartmann, S., Wex, H., Clauss, T., Voigtländer, J., and Stratmann, F.: Heterogeneous ice nucleation: exploring the transition from stochastic to singular freezing behavior, Atmos. Chem. Phys., 11, 8767-8775, doi:10.5194/acp11-8767-2011, 2011.

Phillips, V. T., DeMott, P. J., and Andronache, C.: An empirical parameterization of heterogeneous ice nucleation for multiple chemical species of aerosol, J. Atmos. Sci., 65, 2757-2783, 2008.

Phillips, V. T., Demott, P. J., Andronache, C., Pratt, K. A., Prather, K. A., Subramanian, R., and Twohy, C.: Improvements to an empirical parameterization of heterogeneous ice nucleation and its comparison with observations, J. Atmos. Sci., 70, 378409, 2013.

Pinty, J. and Jabouille, P.: A mixed-phase cloud parameterization for use in a mesoscale non-hydrostatic model: simulations of a squall line and of orographic precipitations, in: Conf. on Cloud Physics, 17-21 August 1998, Everett, Washington, 217-220, 1998.

Press, W. H., Teukolsky, S. A., Vetterling, W. T., and Flannery, B. P.: Numerical Recipes in FORTRAN: The Art of Scientific Computing, Cambridge Univ. Press, New York, 963 pp., 1992.

Pruppacher, H. R.: A new look at homogeneous ice nucleation in supercooled water drops, J. Atmos. Sci., 52, 1924-1933, doi:10.1175/1520-0469(1995)052<1924:ANLAHI>2.0.CO;2, 1995.

Pruppacher, H. R. and Klett, J. D.: Microphysics of Clouds and Precipitation, Kluwer Academic Publishers, Dordrecht and Boston, 1997.

Reisin, T., Levin, Z., and Tzivion, S.: Rain production in convective clouds as simulated in an axisymmetric model with detailed microphysics. Part I: Description of the model, J. Atmos. Sci., 53, 497-519, 1996.

Rosenfeld, D., Lohmann, U., Raga, G. B., O’Dowd, C. D., Kulmala, M., Fuzzi, S., Reissell, A., and Andreae, M. O.: Flood or drought: how do aerosols affect precipitation?, Science, 321, 1309-1313, 2008.

Saleeby, S. M. and van den Heever, S. C.: Developments in the CSU-RAMS aerosol model: emissions, nucleation, regeneration, deposition, and radiation, J. Appl. Meteorol. Clim., 52, 26012622, 2013.

Schär, C., Leuenberger, D., Fuhrer, O., Lüthi, D., and Girard, C.: A new terrain-following vertical coordinate formulation for atmospheric prediction models, Mon. Weather Rev., 130, 2459-2480, 2002.

Seifert, A. and Beheng, K.: A two-moment cloud microphysics parameterization for mixed-phase clouds. Part 1: Model description, Meteorol. Atmos. Phys., 92, 45-66, 2006. 
Seity, Y., Brousseau, P., Malardel, S., Hello, G., Bénard, P., Bouttier, F., Lac, C., and Masson, V.: The AROME-France convective-scale operational model, Mon. Weather Rev., 139, 976-991, 2011.

Slinn, W.: Precipitation scavenging, in: Atmospheric Sciences and Power Production - 1979, Division of biomedical environment research, US department of energy, Washington D.C., chapter 11, 1983.

Storer, R. L., van den Heever, S. C., and L'Ecuyer, T. S.: Observations of aerosol-induced convective invigoration in the tropical east Atlantic, J. Geophys. Res.-Atmos., 119, 3963-3975, doi:10.1002/2013jd020272, 2014.

Tao, W.-K., Chen, J.-P., Li, Z., Wang, C., and Zhang, C.: Impact of aerosols on convective clouds and precipitation, Rev. Geophys., 50, RG2001, doi:10.1029/2011RG000369, 2012.

Thompson, G. and Eidhammer, T.: A study of aerosol impacts on clouds and precipitation development in a large winter cyclone, J. Atmos. Sci., 71, 3636-3658, 2014.

Thompson, G., Field, P. R., Rasmussen, R. M., and Hall, W. D.: Explicit forecasts of winter precipitation using an improved bulk microphysics scheme. Part II: Implementation of a new snow parameterization, Mon. Weather Rev., 136, 5095-5115, 2008.

Tripoli, G. J., Flatau, P. J., and Cotton, W. R.: Generalized microphysics scheme for use in mesoscale/cloud models, in: reprints from the 10th International Cloud Physics Conference, 15-20 August 1988, Bad Homburg, Germany, Vol. 1, 109-111, available at: http://adsabs.harvard.edu/abs/1988clph.conf..109T (last access: 2 September 2015), 1988.
Tulet, P., Crassier, V., Cousin, F., Suhre, K., and Rosset, R.: ORILAM, a three-moment lognormal aerosol scheme for mesoscale atmospheric model: online coupling into the MesoNH-C model and validation on the Escompte campaign, J. Geophys. Res.-Atmos., 110, D18201, doi:10.1029/2004JD005716, 2005.

Twomey, S.: The nuclei of natural cloud formation part II: The supersaturation in natural clouds and the variation of cloud droplet concentration, Geofisica pura e applicata, 43, 243-249, 1959.

Twomey, S.: The influence of pollution on the shortwave albedo of clouds, J. Atmos. Sci., 34, 1149-1152, 1977.

Tzivion, S., Feingold, G., and Levin, Z.: The evolution of raindrop spectra. Part II: Collisional collection/breakup and evaporation in a rainshaft, J. Atmos. Sci., 46, 3312-3328, 1989.

Vié, B. and Pinty, J.-P.: LIMA: a two-moment mixed-phase microphysical scheme driven by a multimodal population of cloud condensation nuclei and ice freezing nuclei, in: 14th AMS conference on cloud physics, 7-11 July, poster number 27, Boston, 2014.

Wall, C., Zipser, E., and Liu, C.: An investigation of the aerosol indirect effect on convective intensity using satellite observations, J. Atmos. Sci., 71, 430-447, 2014. 